WORKING PAPER $\cdot$ NO. 2020-91

\title{
Is Attention Produced Rationally?
}

Erin T. Bronchetti, Judd B. Kessler, Ellen B. Magenheim, Dmitry Taubinsky, and Eric Zwick JUNE 2020

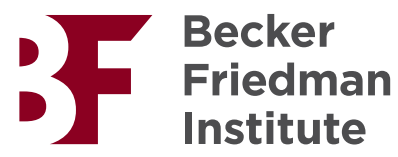


Is Attention Produced Rationally?

Erin T. Bronchetti, Judd B. Kessler, Ellen B. Magenheim, Dmitry Taubinsky, and Eric Zwick

June 2020

JEL No. C91,C93,D91

\begin{abstract}
$\underline{\text { ABSTRACT }}$
A large and growing literature shows that attention-increasing interventions, such as reminders and planning prompts, can promote important behaviors. This paper develops a method to investigate whether people value attention-increasing tools rationally. We characterize how the demand for attention improvements must vary with the pecuniary incentive to be attentive and develop quantitative tests of rational inattention that we deploy in two experiments. The first is an experiment with an online education platform run in the field $(n=1,373)$, in which we randomize incentives to complete course modules and incentives to make plans to complete the modules. The second is an online survey-completion experiment $(n=944)$, in which we randomize incentives to complete a survey three weeks later and the price of reminders to complete the survey. In both experiments, as incentives to complete a task increase, demand for attentionimproving technologies also increases. However, our tests suggest that the increase in demand for attention improvements is too small relative to the null of full rationality, indicating that people underuse attention-increasing tools. In our second experiment, we estimate that individuals undervalue the benefits of reminders by $59 \%$.
\end{abstract}

Erin T. Bronchetti

Department of Economics

Swarthmore College

500 College Avenue

Swarthmore, PA 19081-1397

ebronch1@swarthmore.edu

Judd B. Kessler

The Wharton School

University of Pennsylvania

3620 Locust Walk

Philadelphia, PA 19104

and NBER

judd.kessler@wharton.upenn.edu

Ellen B. Magenheim

Swarthmore College

Department of Economics

500 College Avenue

Swarthmore, PA 19081-1397

emagenh1@swarthmore.edu
Dmitry Taubinsky

University of California, Berkeley

Department of Economics

530 Evans Hall \#3880

Berkeley, CA 94720-3880

and NBER

dmitry.taubinsky@berkeley.edu

Eric Zwick

Booth School of Business

University of Chicago

5807 South Woodlawn Avenue

Chicago, IL 60637

and NBER

ezwick@chicagobooth.edu 


\section{Introduction}

A large and rapidly growing body of work shows that provision of ostensibly small "nudges" to people's attention - such as reminders and planning prompts - can have significant effects on behaviors in economically important domains such as medical compliance, educational attainment, savings, loan repayment, voting, and charitable donation. ${ }^{1}$ How can such simple interventions have such significant effects? After all, the market already provides individuals with many opportunities to acquire reminder technologies and plan-making tools in the form of various smartphone and computer applications, online calendars, smart-caps on pill bottles, and many others. If these various attention-increasing tools were indeed valuable to individuals, wouldn't individuals already utilize them, and therefore not be affected by external provision of additional attention nudges?

One possibility is that individuals can perfectly forecast their attention levels with and without various attention-increasing tools - i.e., their attention production function-but that the costs of the tools exceed the benefits. In addition to any pecuniary costs, reminders and plan-making tools may carry private nuisance costs (see, e.g., Damgaard and Gravert, 2018), time costs, or detract scarce attention from other important tasks (Nafziger, forthcoming). Under this "rational inattention" hypothesis (for reviews, see Caplin, 2016; Maćkowiak et al., 2018; Gabaix, 2019), external interventions may be suboptimal as individuals are already equating marginal benefits to marginal costs in setting their optimal level of attention. ${ }^{2}$

Another possibility is that individuals misunderstand their attention production functions and, in particular, do not appreciate the value of creating reminders and implementation plans. For example, individuals who are overconfident about their future attentiveness may systematically underestimate the value of reminders. In this case, despite a rich offering of attention enhancements by the market, there is still a market failure because individuals' demand for attention-increasing technologies will be below the optimum. In a world with such market failures, promoting take-up of attention-improving technologies could increase efficiency and welfare, as it would lead to investment in attention improvements that are closer to individuals' optima.

\footnotetext{
${ }^{1}$ See, e.g., Nickerson and Rogers (2010); Cadena and Schoar (2011); Milkman et al. (2011, 2013); Altmann and Traxler (2014); Castleman and Page (2016); Bronchetti et al. (2015); Karlan et al. (2016); Calzolari and Nardotto (2017); Damgaard and Gravert (2018); Marx and Turner (2019); and see Rogers et al. (2015) for a review. But see also Carrera et al. (2018) and Oreopoulos et al. (forthcoming) for examples of null effects.

${ }^{2}$ Important exceptions include situations in which it is cheaper for a policymaker to create a reminder or plan-making prompt than it is for individuals themselves and situations in which the behavior under consideration generates positive externalities so that the private optimum is different from the social optimum. But even with these nuances, whether individuals' investment in attention-improving technologies is at or below their private optima is a crucial question for cost-benefit analysis.
} 
This paper develops a method to investigate whether individuals rationally value attentionimproving technologies. We deploy this method in two complementary experiments.

Our method builds on the Caplin et al. (forthcominga) characterization of costly attention models using a competitive supply framework. The key insight behind the testable predictions of full rationality that we develop is to examine not only how the attention-increasing technologies increase the likelihood of completing the task, but also how pecuniary incentives to complete the task affect individuals' propensity to obtain the attention-increasing technologies.

More specifically, the first prediction is a precise condition on how individuals' willingness to pay for the attention-increasing technology changes with the pecuniary rewards for the task. The second prediction is a form of a Slutsky Symmetry condition, which states that the impact of task-completion incentives on take-up of the attention-improving technology is equal to the impact of the price of the attention-increasing technology on the propensity to complete the task. ${ }^{3}$

Guided by this framework, we carry out two experiments. The first is an experiment run in the field with 1,373 students and alumni from six Philadelphia-area colleges who enrolled in an 8-week online coding course. ${ }^{4}$ The experiment randomized incentives to complete three 15-minute coding lessons each week and randomized incentives to make a plan to complete three 15-minute course modules each week. Making a plan involved clicking a link that automatically created three 15-minute events in the participant's online calendar of choice for the following week and allowed the participant to rearrange the planned events to suit their schedule.

We document three key facts in our first experiment. First, use of our plan-making tool increased the likelihood of completing coding lessons, especially in the initial weeks. ${ }^{5}$ Second, take-up of our plan-making tool was elastic to the direct incentives for plan-making, but remained below 100 percent, even with the incentives. The combination of incomplete take-up and the positive elasticity suggests that the use of our tool imposes internal or "nuisance" costs on at least some individuals. Third, we find that take-up of our planmaking tool increased with incentives for completing coding lessons.

This third result is consistent with the qualitative rational inattention prediction that individuals should value attention-improving technologies more when the rewards for com-

\footnotetext{
${ }^{3}$ See Gabaix (2019) for a discussion about testing Slutsky Symmetry as an empirical strategy for testing limited attention.

${ }^{4}$ Setting our experiment in an educational domain has the appeal that it requires a repeated investment of time, involves an intrinsic reward, and participants may fail to follow through on their intentions despite being highly motivated.

${ }^{5}$ Because online calendars typically have built-in reminder features for planned events, the plan-making tool can be thought of as providing a combined plan and reminder.
} 
pleting a task are higher. At the same time, we estimate that the impact of completion incentives on plan-making is quantitatively too small relative to the Slutsky Symmetry condition, suggesting that participants undervalue the plan-making tool. However, our confidence intervals are wide and do not permit us to reject the null of full rationality at conventional levels.

Our second experiment is an online survey-completion experiment that elicits richer data that allows us to fully quantify the demand for a reminder technology and to test the first prediction from our model. The richer data also generates greater statistical power. The study was conducted on Amazon Mechanical Turk (MTurk) with 944 participants. Participants who enrolled in the study were offered a bonus for completing a survey that would only be accessible for a week-long period beginning in three weeks' time. In the main part of the study, we elicited participants' willingness to pay (WTP) for a set of three emails reminding participants to complete the survey. We elicited their WTP for these reminder emails for various bonuses they might receive for completing the survey. We then introduced exogenous variation in whether participants received the reminders.

We find that WTP for reminders increased significantly with the size of the bonus for completing the survey. However, this relationship is weaker than the predicted relationship under the null of full rationality. The average impact of reminders on completing the survey is 37 percentage points, which implies that when the completion bonus is increased by $\$ 1$, rational individuals should increase their WTP for the reminders by $\$ 0.37$, on average. Instead, we find that participants' WTP only increases by $\$ 0.15$, on average. This significant difference implies that individuals do not fully appreciate the value of the reminders.

Collectively, these results show that while individuals are willing to pay more for attention improvements when the stakes are higher, they do not do so as much as the full rationality benchmark predicts. In other words, individuals appear to undervalue attention-improving technologies. This finding suggests that external attention-increasing interventions can increase efficiency by aligning individuals' attention levels with their private optima.

Our results contribute to the literature in several ways. First, we build off of the supply theory framework developed by Caplin et al. (forthcominga) to develop a method to assess whether individuals understand their attention production functions and to test models of rational inattention. Despite the recent proliferation of work on rational inattention, surprisingly little work has been done on individuals' understanding of the limitations of their attention. ${ }^{6}$

\footnotetext{
${ }^{6}$ More work is done on whether individuals' information acquisition strategies and subsequent behavior align with the predictions of rationality. See, e.g., Gabaix et al. (2006); Hanna et al. (2014); Bartos et al. (2016); Martin (2016); Dean and Neligh (2018); Ambuehl et al. (2018); Caplin et al. (forthcominga); Carvalho and Silverman (2019).
} 
Second, we describe two empirical implementations of our method. We demonstrate how to deploy our method in both field and lab settings, across different domains, and evaluating different attention-increasing technologies. We demonstrate how to evaluate whether individuals optimally value attention-increasing activities both by directly measuring willingness-to-pay for an attention-increasing technology and by leveraging our Slutsky Symmetry condition. Both implementations find evidence that individuals undervalue and underuse attention-increasing technologies.

Third, while a large body of work looks at the impact of attention-increasing technologies on behavior, our main advance is to study individuals' demand for attention-increasing technologies. By studying this new comparative static, we provide a link between this reduced-form empirical literature and recent advances in the modeling of rational inattention. Better understanding whether individuals invest in their attention optimally is a necessary input into a comprehensive evaluation of the costs and benefits of deploying reminders, plan-making prompts, and other behavioral nudges.

Perhaps closest to our work, Ericson (2011) and Tasoff and Letzler (2014) conduct lab experiments that find that individuals' willingness to pay for a rebate exceeds the expected returns because individuals' use of the rebate is low. This result suggests overestimation of future attention to the rebate, although naiveté about other psychological biases, such as present focus, could also play a role. Our results complement Ericson (2011) and Tasoff and Letzler (2014) by developing new methods to directly study individuals' valuations of attention-increasing technologies, both in field and in online experiments. ${ }^{7}$

The rest of the paper proceeds as follows. Section 2 presents our theoretical framework. Section 3 describes the online education experiment and presents the results. Section 4 describes the online survey experiment and presents the results. Section 5 concludes with a discussion of other potential applications of our framework in both laboratory and field settings.

\section{Theoretical framework}

We consider individuals who choose a level of costly attention, which is needed to (correctly) complete a task. The level of attention can correspond to the likelihood of being attentive to the task in the future, as in our experiments, or to the likelihood of correctly solving a cognitively demanding or psychometric task, as in the lab-experimental literature on rational inattention (e.g., Dean and Neligh, 2018; Ambuehl et al., 2018; Caplin et al., forthcominga) or the field-experimental literature studying cognitively effortful production (e.g., Dean,

\footnotetext{
${ }^{7}$ See also Taubinsky (2014) and Ericson (2017) for modeling of economic implications.
} 
2019; Kaur et al., 2019; Bessone et al., 2020). We narrate our model in the context of a structure that most closely resembles our experiments, and then explain how it applies to other settings.

In the context of our specific experiments, we think of individuals as making three decisions. First, individuals choose an "attention production function." In the context of our experiments, this is a choice of whether individuals take up our plan-making tool (experiment 1) or our reminder tool (experiment 2). Second, individuals select other ways of increasing attention to the task, such as setting their own reminders, engaging in internal "memory rehearsal" (e.g., Mullainathan, 2002), or asking others to remind them. Third, individuals choose whether or not to complete the task if they remain attentive to it. If they are not attentive, they default to not completing the task.

In principle, we could model the first- and second-step choices as occurring simultaneously. However, because the second-step choices are unobservable to the analyst, we formally distinguish them from the observable choices of attention technologies in our experiments.

To formalize, individuals $i$ first make a choice $j \in\{0,1\}$ between attention cost functions $K_{i}^{0}(\mu)$ and $K_{i}^{1}(\mu)$, where the argument $\mu$ is the probability of being attentive to the task. We let $p$ denote the incremental cost of choosing $j=1$ over $j=0$. In our online education experiment, $-p$ corresponds to the incentives we create for choosing our plan-making tool in the first experiment, while in our online survey experiment $p$ is the price of our reminders.

Individual differences in $K_{i}^{0}$ and/or $K_{i}^{1}$ could result from individual differences in baseline attentiveness, differences in how well-suited the specific attention-improving technology is to an individual's needs, or differences in the nuisance costs of reminders and the personal and social costs of failing to execute a plan that one creates. The difference between $K_{i}^{1}$ and $K_{i}^{0}$ could also capture, in reduced-form, the potential indirect costs of having one's attention to other activities reduced.

After choosing $j \in\{0,1\}$, individuals choose $\mu$, the probability of being attentive to the task in the future, at cost $K^{j}(\mu)$. This corresponds to the unobservable investments in attention we described above (e.g., setting their own reminders or engaging in memory rehearsal). If individuals are inattentive to the task, they default to $a=0$. If individuals are attentive, they choose whether or not to complete the task, with action $a=1$ denoting completing the task and $a=0$ denoting not completing the task.

For expositional simplicity, we assume here that the benefits of choosing $a=1$ over $a=0$ are a deterministic value $r+b_{i}$, where $b_{i}>0$ is the intrinsic benefit and $r$ is the observable pecuniary incentive. This assumption is easily relaxed without altering any results, as shown in Appendix A.1 and A.2.

Given an attention technology $K^{j}$, the net utility benefit of an attention level $\mu$ is thus 
$\left(b_{i}+r\right) \mu-K_{i}^{j}(\mu)$. Under the assumption that utility is locally linear in the pecuniary incentives, rationally inattentive individuals choose $j$ and $\mu$ to maximize $\left(b_{i}+r\right) \mu-K_{i}^{j}(\mu)-p j$.

Our main result characterizes testable restrictions of the rationality assumption on a set of statistics that we measure in our two experiments. The first statistic is the willingness to pay (WTP) for technology $j=1$; that is, the highest $p$ at which $j=1$ is preferred to $j=0$. Note that if the nuisance cost of $j=1$ is sufficiently high, this statistic can be negative, even if $j=1$ lowers the marginal cost of attention. Average WTP is given by

$$
\bar{W}(r):=\mathbb{E}\left[\max _{\mu}\left(\left(b_{i}+r\right) \mu-K_{i}^{1}(\mu)\right)-\max _{\mu}\left(\left(b_{i}+r\right) \mu-K_{i}^{0}(\mu)\right)\right]
$$

We also consider $\operatorname{Pr}(j=1 \mid p, r)$, the probability of individuals choosing technology $j=1$ given financial incentives $p$ and $r$, and $\operatorname{Pr}(a=1 \mid p, r)$, the probability of individuals doing the task (i.e., choosing $a=1$ ) given incentives $p$ and $r$. In the set-up here, the latter is simply the probability of being attentive, but more generally this probability may be smaller than $\mu$ if the net benefits of choosing $a=1$ are not always positive. Finally, we consider $\operatorname{Pr}(a=1 \mid j, r)$, the probability of individuals choosing $a=1$ if individuals are exogenously assigned attention technology $j$.

Our main assumption - which we state formally in Appendix A.1 - is that individual differences are sufficiently "smoothly distributed" such that $\bar{W}(r), \operatorname{Pr}(j=1 \mid p, r)$, and $\operatorname{Pr}(a=1 \mid p, r)$ are differentiable functions of $p$ and $r$. Under this assumption, rational allocation of attention implies the following testable restrictions on these statistics:

Proposition 1. Average willingness to pay for the attention-increasing technology, as a function of the task-completion incentive $r$, satisfies

$$
\frac{d}{d r} \bar{W}(r)=\operatorname{Pr}(a=1 \mid j=1, r)-\operatorname{Pr}(a=1 \mid j=0, r) .
$$

The likelihood of choosing technology $j=1$ and the likelihood of completing the task, as functions of the task-completion incentive $r$ and the technology price $p$, satisfy the equality

$$
\frac{d}{d r} \operatorname{Pr}(j=1 \mid p, r)=-\frac{d}{d p} \operatorname{Pr}(a=1 \mid p, r) .
$$

Equation (1) of Proposition 1 states that, if individuals are more likely to choose $a=1$ by, e.g., $10 \%$ under attention technology $j=1$ and incentive $r$, then a $\$ 1$ increase in $r$ should increase individuals' average willingness to pay for $j=1$ by approximately $\$ 0.10$. The result and intuition follow from the Envelope Theorem. Rationality implies that a small increase $d r$ in the task incentive should be worth $\operatorname{Pr}(a=1 \mid j=1, r) d r$ to individuals exogenously assigned technology $j=1$, and should be worth $\operatorname{Pr}(a=1 \mid j=0, r) d r$ to 
individuals exogenously assigned technology $j=0$. Consequently, the average impact on the WTP for $j=1$ is $(\operatorname{Pr}(a=1 \mid j=1, r)-\operatorname{Pr}(a=1 \mid j=0, r)) d r$.

Figure 1 illustrates this intuition graphically for a representative individual, for the case in which the marginal costs are linear. In this case, the likelihood of executing the task equals the chosen level of attention $\mu$. In analogy to standard theories of competitive supply, individuals' choice of $\mu$ with attention technology $j$ is determined by the intersection of the marginal benefit curve $r+b$ and the marginal cost curve $\frac{\partial}{\partial \mu} K^{j}$. As in theories of competitive supply, the total surplus of an individual with technology $j=0$ at incentive $r$ is equal to the area of triangle OAD, which is $(r+b) \operatorname{Pr}(a=1 \mid j=0)-K^{0}(0)$, where $K^{0}(0)$ can be thought of as the "fixed cost." Similarly, the total surplus of an individual with technology $j=1$ is equal to the area of triangle OAF, which is $(r+b) \operatorname{Pr}(a=1 \mid j=1)-K^{1}(0)$. Increasing the incentives $r$ by an amount $\Delta$ increases surplus by an amount ABCD under technology $j=0$, and by an amount ABEF under technology $j=1$. The change in WTP for technology $j=1$ is thus given by the area DCEF. In the limit of very small $\Delta$, the areas of ABCD and ABEF are approximately $\Delta \cdot \operatorname{Pr}(a=1 \mid j=0)$ and $\Delta \cdot \operatorname{Pr}(a=1 \mid j=1)$, respectively, and the WTP for $j=1$ over $j=0$ is thus $\Delta \cdot[\operatorname{Pr}(a=1 \mid j=1)-\operatorname{Pr}(a=1 \mid j=0)]$.

It is important to note that the difference in fixed costs, $K^{1}(0)-K^{0}(0)$, may result from the potential nuisance costs of attention-improving technologies - which is consistent with negative WTP for reminders by some individuals in our second experiment. Thus, the value of a reminder cannot be equated with its impact on the change in expected earnings $r \operatorname{Pr}(a=1)$. Simply documenting that, for example, individuals' valuations for a reminder that increases their chance of earning $\$ 20$ by $10 \%$ is smaller than $\$ 2$ is not a rejection of rational valuation of the reminder, since nuisance costs could make a rational individual value the reminder less than or more than $\$ 2$. Our more robust test focuses instead on how individuals' valuations of the reminder change as the pecuniary incentives for being attentive change.

The condition in equation (1) requires rich data that is difficult to collect in some field settings and that we do not have in our first experiment. Equation (2) builds on equation (1) by characterizing how the probability of choosing $j=1$ and the probability of choosing $a=1$ are related to each other. The condition in equation (2) formalizes the basic intuition that if attention is allocated optimally, then increasing the incentives for choosing $a=1$ should increase the desire to adopt a technology that increases the likelihood of choosing $a=1$. But while the qualitative comparative static could still be consistent with individuals under- or over-valuing the benefits of attention technology improvements, the quantitative condition clarifies exactly how much individuals should seek attention technology improvements.

The condition is a variation on the Slutsky Symmetry condition that cross-price elastici- 
ties of compensated demand functions must be equal to each other. Intuitively, $-\frac{d}{d p} \operatorname{Pr}(a=$ $1 \mid p, r)$ is an indication of how adoption of technology $j=1$ impacts the probability of choosing $a=1$. In our online education experiment, this derivative is the average impact of our plan-making incentives on the likelihood of completing course modules. The higher this number is, the higher the impact of our plan-making tool on the likelihood of completing the course modules will be. And the higher is the impact of the plan-making tool, the higher is the impact of a small change in $r$ on its value, as formalized in the first part of Proposition 1. This translates to a higher derivative $\frac{d}{d r} \operatorname{Pr}(j=1 \mid p, r)$.

\subsection{Applications to other settings}

Our framework can be implemented for a variety of other attentional tasks studied in lab and field experiments. Suppose that $b=0$ is fixed so that the expected payoff is simply $\mu r$. This corresponds to psychometric experiments such as those of Dean and Neligh (2018) and Caplin et al. (forthcominga), or settings where employees exert mental effort under a piece-rate incentive scheme (e.g., Dean, 2019; Kaur et al., 2019; Bessone et al., 2020). The observable choice of $K^{j}$ can capture the choice of task difficulty, decision aids, or the level of distraction in the environment. The choice of $\mu$ conditional on $j$ corresponds to various forms of exerting mental effort not directly observable to the analyst. The observable outcome $a$ simply captures whether the individual executed the task correctly or not.

Our modeling of attention as a production technology makes use of results in Caplin et al. (forthcominga), which shows that standard rational inattention models (e.g., Sims, 2003; Matejka and McKay, 2015; Caplin and Dean, 2015; Caplin et al., forthcomingb) can be represented by a production model in which individuals pay a cost to obtain a probability $\mu$ of taking the right action. The Caplin et al. (forthcominga) results imply that our modeling framework makes minimal assumptions about the structure and dimensionality of attention allocation.

\subsection{Deviations from the full-rationality benchmark}

Deviations from the full-rationality implications derived in Proposition 1 can be used to quantify behavioral biases. Misperception of attention production functions will lead to violations of the conditions in Proposition 1. For example, if individuals are overconfident about the likelihood of being attentive in the future, they will undervalue improvements to their attention production function. In particular, if individuals think that their likelihood of being inattentive is only $\theta<1$ as high as it actually is, then $\frac{d}{d r} \bar{W}(r)=$ $\theta\left[\operatorname{Pr}\left(a=1 \mid K_{1}, r\right)-\operatorname{Pr}\left(a=1 \mid K_{0}, r\right)\right]$ and $\frac{d}{d r} \operatorname{Pr}\left(K_{1} \mid p, r\right)=-\theta \frac{d}{d p} \operatorname{Pr}(a=1 \mid p, r)$. Deviations 
from the conditions in Proposition 1 can thus provide estimates of parametric models of overconfidence. We formalize these claims in Appendix A.3.

Of course, such a parametric model of overconfidence need to not be the only possible micro-foundation. For example, individuals could under-appreciate the efficacy of particular attention-increasing technologies, but be well-calibrated about their level of attention in the absence of attention-increasing technologies. Rejection of the conditions in Proposition 1 rejects the rational inattention assumption in a robust way that is not tied to any particular parametric model of misperceptions.

\section{Online Education Experiment}

Our first experiment was designed around the Slutsky Symmetry test in Equation (2) of Proposition 1. It investigates how individuals respond to incentives that reward task completion and incentives that reward plan making, in the context of completing the coursework of an online computer coding course. We conducted a six-arm experiment in which participants were randomly assigned to groups that faced different levels of financial incentives for task completion (completing at least three 15-minutes sessions of the online coding course in a week) and plan making (creating calendar events specifying when during the week they would complete the coding lessons). The experiment lasted for eight weeks during the fall of 2018 .

We partnered with Code Avengers, an online interactive platform for learning to code, to offer participants a free, 8-week course in three different programming languages (HTML/CSS, Javascript, and Web Dev). ${ }^{8}$ We choose an educational domain because it requires a repeated investment of time, involves an intrinsic reward, and participants may fail to appropriately plan to complete their courswork. It also allows our experiment to contribute to the growing literature on behavioral economics interventions in education (see, e.g., Castleman and Page, 2016; Levitt et al., 2016; Damgaard and Nielsen, 2018).

Our results provide evidence on the responsiveness of plan making to small incentives and on the degree to which plan making affects task completion. Importantly, our experiment also provides estimates of the two statistics necessary to perform the Slutsky Symmetry test: how task completion responds to incentives to plan, and how plan making responds to incentives to complete the task.

\footnotetext{
${ }^{8}$ These languages are commonly used tools for building modern web sites. See http://www.codeavengers.com for more details.
} 


\subsection{Design and implementation}

\subsubsection{Subject pool}

We recruited students and recent alumni from six Philadelphia-area colleges using an email campaign. Enrollees were eligible to be included in our study if they reported in the onboarding survey that they regularly used either Google Calendar or Apple's iCal as an electronic calendar. Perhaps due to the relative youth of the subject pool, usage rates were high, at around 60-70 percent. Recruitment resulted in a pool of 1,373 study-eligible participants.

Table 1 presents characteristics of the subject pool; females, first-years, and seniors were most likely to participate. Participants were highly motivated and expressed strong intentions to complete the course. In a survey of a random subset of participants, subjects reported their expected likelihood of completing the course was 79 percent. They reported that likelihood as 86 percent if they were to make a plan each week for when to do the coding lessons, 90 percent if they received $\$ 2$ each week for completing the coding lessons, and 92 percent if they were to receive $\$ 5$ each week for completing the coding lessons.

\subsubsection{Implementation}

Just before the 8-week course began, participants received an introductory email with information on their treatment assignment (see Appendix Figures B.1, B.2, and B.3). This email also contained a recommendation that participants aim to complete three, 15-minute sessions of the coding course per week, a prompt to encourage participants to make a plan for when they would do the coding lessons, and a link to make plans for working on the coding lessons, which would be created in their electronic calendars. Participants who were eligible for financial rewards were informed that they would be paid their cumulative earnings in the form of an Amazon gift card at the end of the 8-week period.

Over 90 percent of participants opened the initial emails that informed them of the incentives they faced (i.e., their treatment group), giving us confidence that most were aware of the incentives for which they were eligible. As expected from the random assignment of treatment, email opening rates were very similar across treatment groups, ranging from $88 \%$ to $91 \%$.

After the course had begun, all participants received a reminder email at the start of each week. The reminder email contained the same recommendation, planning prompt, and a link to create plans as the initial email (Appendix Figure B.4). 


\subsubsection{Experimental design}

The experiment consisted of a control group and five treatment arms, with varying levels of incentives for plan making and/or coding task completion. Participants assigned to the control group received the initial and reminder emails encouraging them to plan and complete the coding lessons and offering them the plan-making tool, but they were not eligible for financial rewards.

Those randomly assigned to the two Pay-to-Plan treatments received either $\$ 1$ or $\$ 2$ for making a plan for when to do their coding lessons that week (i.e., clicking the plan-making link within the weekly email). In the two Pay-to-Code treatments, participants received either $\$ 2$ or $\$ 5$ for completing three 15 -minute sessions of the coding course during the week. Finally, participants in the Combination treatment arm were paid $\$ 1$ for making a plan plus $\$ 2$ if they completed three 15-minute sessions of the coding course during the week. Participants could earn these amounts each week, regardless of what they had done in previous weeks. In addition, making a plan did not restrict when a participant could do the coding lessons (i.e., participants in the Pay-to-Code and Combination treatments could complete the 15-minute sessions at any time during the week and still earn their coding-task incentives, regardless of whether or not they made a plan or when they had scheduled the three 15-minute sessions).

To measure plan making, we tracked whether a participant clicked on the provided planmaking link to create calendar events for when they planned to complete the 15-minute coding sessions. ${ }^{9}$ Consistent with our theoretical model, this observable plan making is not the only available attention-increasing technology, or even the only available plan-making opportunity. For example, some participants might have other means of making plans or might directly edit their calendars without using our link. However, nearly forty percent of the control group clicked to make a plan in the first week, despite receiving no financial rewards for doing so, and participants with higher incentives for completing the coding task were more likely to use the plan-making tool, implying that our plan-making tool was not a perfect substitute for the plan making individuals would do otherwise. ${ }^{10}$ In part, this may be because the act of making a plan by using our link generates an internal cue, as theorized in the implementation intentions literature (Gollwitzer and Sheeran, 2006).

\footnotetext{
${ }^{9}$ When participants clicked on the plan-making link, they were given three default times, which they could change. This default ensured that as long as a participant clicked on the link, a calendar event would be created.

${ }^{10}$ Our theoretical framework only requires that the plan-making tool we offer is not a perfect substitute to other forms of planning individuals already undertake. Heterogeneity in attention cost functions accommodates the possibility that some participants who use our plan-making tool simply substituted from creating their own calendar reminders while others who use our plan-making tool would not have created a plan themselves.
} 
To measure completion of the coding coursework, we received real-time, backend data from Code Avengers on the number of minutes participants spent actively working on their coding coursework each day. The session timer stopped running after approximately 30 seconds of inactivity within the course. Once they had completed 15 minutes of active work, participants were notified with a pop-up that congratulated them but did not prevent or discourage them from continuing.

\subsection{Results}

\subsubsection{Empirical framework}

Our primary analysis focuses on measuring the effect of plan-making and coding-task incentives on plan making and coding task completion. We estimate treatment effects using regressions of the form

$$
y_{i c t}=\beta T_{i c t}+\alpha_{c}+\alpha_{t}+\gamma X_{i}+\varepsilon_{i c t},
$$

where $y_{\text {ict }}$ measures either plan making or completing at least $\tau \in\{0,10,20,30,40,45,50,60\}$ minutes in week $t$ for participant $i$ at campus $c$. We include fixed effects $\alpha_{c}$ for campus interacted with student status (i.e., current student or alumni), which was the level at which we randomized. We also control for course week $\alpha_{t}$ and a vector of participant characteristics $X_{i}$, but random assignment implies that these additional controls do not affect our estimated treatment effects. Our preferred measure of treatment $T_{i c t}$ is value in dollars of the participant's incentive, which assumes a linear relationship between the incentive and behavior. We also consider a specification with indicators for different incentive sizes. We estimate regressions separately for the Pay-to-Plan sample, which includes the control group and the two Pay-to-Plan treatments, and the Pay-to-Code sample, which includes the control group and the two Pay-to-Code treatments.

\subsubsection{Plan-making incentives}

In Table 2, we estimate the impacts of plan-making incentives on plan making and on coding task completion. The analysis sample includes 705 participants and 8 pooled weekly observations per participant. In Panel A, we estimate the effect of plan-making incentives on the propensity to plan in week 1 , weeks 1 to 4 , and weeks 1 to 8 . Multiple-week outcomes average the indicator for whether a participant made a plan (or completed the coding task) in each week. In Panel B, we estimate the effect of plan-making incentives on the propensity to complete at least 20 minutes or at least 45 minutes of coding during week 1, weeks 1 to 4 , and weeks 1 to 8 , respectively. Although our financial incentives were specifically for 
completing at least 45 minutes of the coding task (i.e., the three 15-minute sessions), we also include the 20-minute benchmark in the main tables and text to show robustness. Appendix Tables B.1 and B.2 consider other time thresholds: 0, 10, 30, 40, 50, and 60 minutes per week. Our interpretation of the results is consistent with the evidence from these alternative thresholds.

The results indicate strong impacts of plan-making incentives on plan making and modest impacts of plan-making incentives on coding task completion. For each $\$ 1$ of plan-making incentive, participants increase their plan making by 11.6 percentage points $(\mathrm{s} . e .=1.3)$ on average over the eight weeks of the study, an increase of $140 \%$ relative to the control group mean of 8.2 percentage points. Plan-making effects are 18.0 percentage points $($ s.e. $=2.0)$ in week 1 , and 14.2 percentage points (s.e.=1.4) on average over weeks 1 to 4 , which suggests an attenuated response over the course of the study. However, the control mean falls even more quickly, from $38.1 \%$ in week 1 , to $15.0 \%$ in the first four weeks, to $8.2 \%$ over the full study, such that the relative impact of plan-making incentives increases over time. Panel A of Appendix Table B.3 shows the effects of the $\$ 1$ and $\$ 2$ plan-making incentives separately.

The treatment effect of plan-making incentives on coding task completion is more modest but still meaningful. Focusing on course completion of at least 45 minutes a week, we find that $\$ 1$ of plan-making incentive increases coding task completion by 3.8 percentage points (s.e. $=1.8$ ) in week 1 , an increase of $22 \%$ relative to the control group mean of 17.4 percentage points. However, the effect declines to a marginally significant 1.7 percentage points (s.e. $=1.2$ ) over weeks 1 to 4 , and to a statistically insignificant 0.6 percentage points (s.e. $=0.9$ ) over weeks 1 to 8 . In Panel $\mathrm{C}$, we combine the plan making and coding task completion estimates in an instrumental variables estimation of the effect of plan making on coding task completion. Making a plan increases the probability of coding task completion by 21 to 22 percentage points in week 1, an $81 \%$ to $124 \%$ increase relative to control group means. This large effect is precisely estimated for week 1 and weeks 1 to 4 but diminishes over the full experimental period. Overall, the results point to the value of plan making for people who have some intrinsic motivation to complete the coding sessions. Panel B of Appendix Table B.3 shows the effects of the $\$ 1$ and $\$ 2$ plan-making incentives separately.

The decrease in treatment effects over time is not surprising, as many participants appear to attrit out of the coding course. Figure 2 plots control group means for plan making and coding task completion over the weeks of the experiment. Engagement in the first two weeks of the study is relatively high in the absence of monetary incentives - control group participation hovers between 20 and 30 percent. However, many participants disengage from both the plan-making tool, which falls close to zero by week 3 , and from continuing the coding course, which falls to 10 percent participation by week 5 , suggesting that motivation 
for the coding course diminished over time.

\subsubsection{Coding-task incentives}

Table 3 estimates the impacts of coding-task incentives on plan making and coding task completion. The analysis sample includes 714 participants and 8 pooled weekly observations per participant. Following the structure of Table 2, in Panel A, we estimate the effect of coding-task incentives on the propensity to plan in week 1, weeks 1 to 4 , and weeks 1 to 8 . In Panel B, we estimate the effect of coding-task incentives on the propensity to complete at least 20 minutes or at least 45 minutes of coding during week 1, weeks 1 to 4 , and weeks 1 to 8 , respectively.

Coding-task incentives have substantial effects on coding task completion, as shown in Panel B. We estimate that each $\$ 1$ of coding-task incentive increases completion rates for 45 -minutes in week 1 by 3.5 percentage points (s.e. $=0.8$ ), an increase of $20 \%$ relative to the control group mean of 17.4 percentage points. For the $\$ 2$ incentive and $\$ 5$ incentive groups, this coefficient implies an increase in the probability of coding task completion of 7 and 17.5 percentage points, respectively, or $40 \%$ and $101 \%$ relative to the control mean of 17.4 percentage points. Again, the treatment effects diminish over time to 2.4 percentage points (s.e. $=0.6$ ) per $\$ 1$ over weeks 1 to 4 , and to 2.0 percentage points (s.e. $=0.5)$ per $\$ 1$ over the eight weeks of the study. ${ }^{11}$

A more novel result is that coding-task incentives also increase the probability of plan making, as shown in Panel A. Column 1 shows that for each $\$ 1$ of coding-task incentive, participants increase their plan making by 2.5 percentage points (s.e. $=0.9$ ) in week 1 , by 1.0 percentage point $($ s.e. $=0.4$ ) in weeks 1 to 4 , and by 0.7 percentage points (s.e. $=0.3$ ) over the eight weeks of the study. Relative to the control group means of $0.38,0.15$, and 0.08 , these correspond to plan making increases of $6.6 \%, 6.7 \%$, and $8.5 \%$ per $\$ 1$ of plan-making incentive.

\footnotetext{
${ }^{11}$ We exclude the Combination treatment from our main analysis and separately evaluate whether this treatment exhibits complementarity effects (i.e., whether combining a $\$ 1$ plan-making incentive with a $\$ 2$ coding-task incentive induces plan making or coding effects that are significantly different from the $\$ 1$ Payto-Plan or $\$ 2$ Pay-to-Code treatments in isolation). For weeks 1 to 8, the Combination treatment effect on plan making is 26.7 percentage points (s.e.=2.6) compared to 23.9 percentage points (s.e. $=2.7$ ) for the $\$ 1$ Pay-to-Plan treatment $(\mathrm{p}$-value of difference $=0.31)$. The Combination treatment effect on average course completion is 3.8 percentage points (s.e. $=2.4$ ) compared to 4.6 percentage points (s.e.=2.1) for the $\$ 2$ Payto-Code treatment $(\mathrm{p}$-value of difference $=0.72)$. Thus, we find no statistically significant complementarity effect of the Combination treatment.
} 


\subsubsection{Symmetry test}

Participants clearly recognize the potential value of plan making in helping them achieve their coding course participation. Yet do they value plan making enough? To answer this question, we compare the cross-price coefficients across the Pay-to-Plan and Pay-to-Code samples, implementing the test in Equation (2) of Proposition 1. The coefficients for $\$ 1$ of plan-making incentives on coding task completion are 0.039, 0.017, and 0.006 in week 1 , weeks 1 to 4 , and weeks 1 to 8, respectively. The analogous coefficients for $\$ 1$ of coding-task incentives on plan making are 0.025, 0.010, and 0.006. The difference in coefficients provides our first test of under-planning, delivering estimates of 0.014 (s.e. $=0.019), 0.007$ (s.e. $=0.012$ ), and -0.0004 (s.e.=0.009), respectively. ${ }^{12}$ The positive sign of the differences, in particular in the early weeks of the study, hints at the possibility that participants might undervalue plan making. However, the standard errors are too wide to draw strong conclusions from this data about whether participants plan optimally.

Figure 3 plots week-by-week coefficients for plan-making and coding-task incentives to illustrate how the effect of incentives evolves over the course of the experiment. The effect of coding-task incentives on plan making is consistently close to zero (after week 1) and tightly estimated. In contrast, the effect of plan-making incentives on coding task completion are positive for the first half of the study and then decay toward zero, with relatively wider confidence intervals. ${ }^{13}$ This fact provides suggestive evidence of under-planning.

\section{Online Survey-Completion Experiment}

Estimates from our field experiment show that incentives for plan-making increase coding task completion, and incentives for coding task completion lead to more plan-making. While this second result is qualitatively consistent with rational management of attention, our estimates are not sufficiently precise to provide a conclusive test of the Slutsky Symmetry condition in Equation (2) of Proposition 1. Similarly, our point estimates are consistent with participants under-appreciating the benefits of plan-making early in the study, but we cannot reject that individuals value the plan-making tool rationally.

To generate more statistical power and to test more directly whether individuals rationally value an attention-increasing technology, we designed and ran a complementary survey-completion experiment on Amazon's Mechanical Turk platform (MTurk). The experiment is tightly tied to the test in Equation (1) of Proposition 1, described in Section 2.

\footnotetext{
${ }^{12}$ Standard errors for coefficient differences are estimated via seemingly unrelated regression.

${ }^{13}$ The difference in standard errors across treatments owes to having higher variance in coding-task incentives $(\$ 0, \$ 2$, and $\$ 5)$ relative to plan-making incentives $(\$ 0, \$ 1$, and $\$ 2)$.
} 
The test states that for individuals who optimally invest in attention increasing technology, a $\$ 1$ increase in the incentive for task completion must increase willingness to pay for such a technology by $\$ 1$ times its efficacy (i.e., by the change in the probability of task completion due to the technology). To show robustness to a new setting, our online experiment replaces plan-making to complete the coding task with email reminders to complete a 20-minute survey.

\subsection{Design and Implementation}

In May of 2019, we initiated a two-part study on MTurk. Our recruitment material informed potential participants that part 1 of the study would require five minutes of time immediately (for which participants were paid a guaranteed $\$ 1$ and had the possibility of earning a bonus), and that they would be invited to participate in part 2 of the study at a later date for additional compensation by accessing a website provided to participants at part 1 of the study.

When participants clicked to begin the study, they were told that part 2 of the studya survey that needed to be completed in one 20-minute sitting - would only be available starting in three weeks and that they would have a one-week window to complete it. ${ }^{14}$

The first part of the study elicited participants' willingness to pay (WTP) for a set of three reminder emails that would come during the one-week window in which participants would be able to complete the survey. The goal was to generate data that would allow us to directly measure how much more participants were willing to pay for reminder emails as the incentive to complete the survey increased.

Participants were informed that their incentive for completing the survey would be either $\$ 2, \$ 3, \$ 4$, or $\$ 5$, and that each was equally likely to be selected. For each of the four possible incentive amounts, participants faced an incentivized multiple price list (MPL) that traded off part 1 bonus payments (up to $\$ 1.50$, which would be paid out a few days after participants completed part 1 of the study) against being sent the three reminder emails to complete the survey. ${ }^{15}$ The four MPLs, one for each possible incentive amount participants could earn for

\footnotetext{
${ }^{14}$ Participants were asked a screening question (see Appendix Figure C.1) about whether they would be available to complete the survey in the designated window. Those who said they would be unable to do so were screened out of the study (see additional details in Appendix C.1). Participants completed the first part of the study on either May 3 or May 7 of 2019. Those who participated on May 3 were able to complete the second part of the study between May 25 and May 31 of 2019. Those who participated on May 7 were able to complete the second part of the study between May 29 and June 4 of 2019.

${ }^{15}$ Part 1 bonus payments were paid out a few days after participants completed part 1 of the study, mitigating concerns that part 1 bonuses would be viewed as being paid immediately, which might have made them particularly valuable from the perspective of a quasi-hyperbolic discounter. The results of Augenblick et al. (2015) and Augenblick (2020) suggest that monetary rewards paid out a few days later are very unlikely to be treated as a form of immediate gratification.
} 
completing the survey, were shown to participants in a random order.

To ensure that participants understood the specific details of the reminder emails, we explained that the emails would come at 12pm ET on the first, middle, and final days of the one-week window when they could complete the survey. ${ }^{16}$ Participants were told that emails would be sent using the MTurk email system — which MTurk uses for communicating with workers on their platform - so participants did not have to provide an email address and the reminder emails would be unlikely to go to spam. Participants were told that the link to the survey would be included in the reminder emails so that initiating the survey would be as easy as clicking a link in the email. Participants were also explicitly told that they would not receive any reminders to complete the survey unless they were selected to receive these three reminder emails. ${ }^{17}$

Appendix Figure C.10 shows an example MPL decision screen. Because nuisance costs can lead participants to have negative WTP for the reminders, the MPL allowed participants to report both positive and negative willingness-to-pay for the reminder emails. ${ }^{18} \mathrm{We}$ anticipated that some participants might be at the extreme ends of the MPL: Top-censored participants choose the option on the left in each row, indicating a WTP for reminders of more than $\$ 1.50$. Bottom-censored participants choose the option on the right in each row, indicating a WTP for reminders of less than $-\$ 1.50$. If a participant was censored on an MPL, we asked them an unincentivized question about how much they would be willing to pay for reminders (if $W T P \geq \$ 1.50$ ) or would need to be paid to accept reminders (if $W T P \leq-\$ 1.50)$. In practice, no participants indicated a $W T P \leq-\$ 1.50$ on any of the MPLs, and thus in our analysis we only discuss top-censored participants. ${ }^{19}$

Participants were told that whichever incentive amount was randomly selected for them would be the bonus they would receive for completing the survey. In addition, they were told that for the randomly selected incentive amount, there was a $10 \%$ chance that one of the rows of that MPL would be randomly selected (each with equal probability) and that

\footnotetext{
${ }^{16}$ The emails were sent on May 25, May 28, and May 31 for those who took part 1 of the study on May 3; and May 29, June 1, and June 4 for those who took part 1 of the study on May 7.

${ }^{17}$ In order to remain in the study, participants needed to correctly answer questions demonstrating their understanding of the compensation structure and conditions for receiving reminders (e.g., answering "True" to the statement: "You will not receive any reminders unless you are selected to get them based on random chance and your choices in part 1.")

${ }^{18}$ Consistency on an MPL requires a participant to always choose the option on the left, always choose the option on the right, or switch from choosing the option on the left to choosing the option on the right in one row of the MPL. Always choosing the option on the right or switching to the right between row 2 and 6 indicates a negative WTP for the reminder emails (weakly negative if the switch occurs in row 6). Switching to the right between rows 7 and 11 or always choosing the option on the left indicates a positive WTP for the reminder emails (weakly positive if the switch occurs in row 7). The approach of allowing both positive and negative WTP is similar to the designs in Allcott and Kessler (2019) and Butera et al. (2019).

${ }^{19}$ Appendix Figures C.11 and C.12 show examples of these questions.
} 
whatever the participant chose in that row would be implemented (i.e., they would receive whatever part 1 bonus payment was indicated in their choice, and they would receive the reminder emails if they chose the option on the left).

Because testing Proposition 1 also requires estimating the effect of the reminder emails on completing the survey, we did not guarantee that one of the MPL rows would be selected. Instead, we randomized $45 \%$ of participants to receive the reminder emails and $45 \%$ of participants not to receive the reminder emails, regardless of their MPL choices. ${ }^{20}$ We use this random variation to estimate the effect of reminder emails on completing the survey. We randomly assign reminder emails in this way, and estimate the effect of reminders using this sample, in order to avoid potential selection bias that might arise if there were a correlation between WTP for reminders and the rate at which individuals completed the survey.

\subsection{Results}

\subsubsection{Sample}

As detailed in Appendix C.1, 1,034 individuals fully completed the first part of the study. Of these, 90 individuals were excluded from analysis for: having an invalid MTurk ID $(n=7)$, accessing the survey after recruitment had been completed $(n=4)$, or having inconsistent MPL responses $(n=79)$. We report on data from the remaining 944 participants. ${ }^{21}$

\subsubsection{How WTP changes with the incentive to complete the survey}

Figure 4 shows CDFs of WTP for the reminder emails for each part 2 incentive level. For uncensored participants, the MPL identifies a range for WTP (e.g., if a participant chooses to get the reminders when they cost 25 cents and not to get the reminders when they cost 50 cents, we infer that the participant values reminders between 25 and 50 cents). We use the midpoint of each WTP range as our estimate of WTP. As the figure shows, participants are willing to pay more for reminders as the incentive to complete the survey in part 2 of the study increases. ${ }^{22}$ In addition, the number of participants who are willing to pay more

\footnotetext{
${ }^{20}$ In addition, all of these participants received a $\$ 1.00$ bonus for completing part 1 of the study.

${ }^{21}$ As detailed in Appendix C.1, our 1,034 number excludes participants who were not allowed to continue with part 1 of the study because they failed to correctly input a captcha or failed to correctly answer understanding questions. An advantage of excluding these participants from the study ex ante - not allowing them to answer any WTP questions - is that it ties our hands to only analyze data from participants who were attentive and clearly understood the study instructions.

${ }^{22}$ While the CDFs look rather identical in the negative WTP region, as the incentives for completing the survey increase, the postive WTP region of the CDFs fall lower and to the right, indicating higher willingness to pay.
} 
than $\$ 1.50$ for the reminder emails - shown as a mass in the CDF at a willingness to pay of 150 cents - increases with the part 2 incentive level. ${ }^{23}$

We formalize the results from Figure 4 in Table 4, combining data from all four incentive levels to estimate how average WTP changes with the incentive to complete the survey. We estimate treatment effects using regressions of the form,

$$
W T P_{i j}=\beta\left[\text { Incentive }_{j}\right]+\gamma_{i}+\varepsilon_{i j}
$$

where $W T P_{i j}$ is participant $i$ 's willingness to pay for reminders given incentive $j$. The coefficient $\beta$ (labeled Incentive (\$) in the table) shows the average effect on WTP of increasing the incentive to complete the survey by $\$ 1 . \gamma_{i}$ are participant fixed effects to account for the possibility that different participants have different average WTP.

Regressions in Table 4 differ in how they handle participants whose WTP is censored by the MPLs. Column (1) shows our baseline specification in which any top-censored WTP estimate is replaced by the median WTP reported in the unincentivized question that we asked each participant who was top-censored on an MPL (see Appendix Figure C.11 and the discussion in Section 4.1). Using the median mitigates potential concerns about participants reporting extreme values to those unincentivized questions. In subsequent columns, we show that our results are robust to multiple approaches to handling censored WTPs.

Results from column (1) suggest that participants are willing to pay 15 cents more on average for every $\$ 1$ increase in the incentive for completing the survey. Column (2) replicates the analysis in column (1) but replaces the median of unincentivized WTP reports of all participants censored at that incentive level with each censored participant's specific WTP report. Results from column (2) are very similar and imply that participants are willing to pay 17 cents more on average for every $\$ 1$ increase in the incentive for completing the survey. Column (3) replaces any censored WTP values with $\$ 5$, the maximum incentive amount, and also estimates that participants are willing to pay 17 cents more on average for every $\$ 1$ increase in the incentive for completing the survey. Finally, column (4) does not attempt to replace the censored WTP values but instead keeps them at $\$ 1.50$ and estimates a Tobit specification to account for the censoring at $\$ 1.50$. This specification estimates participants are willing to pay 6 cents more for every $\$ 1$ increase in the incentive for completing the survey. The difference between the Tobit estimates and columns (1) and (2) of the table suggests that the distribution of WTPs has a thicker right tail than the normal distribution assumed in the Tobit model.

Taken together, the results show that for every $\$ 1$ increase in the incentive for completing

\footnotetext{
${ }^{23}$ The percentage of participants willing to pay more than $\$ 1.50$ is $14 \%$ when the incentive is $\$ 2$ and increases to $25 \%$ when the incentive is $\$ 5$.
} 
the survey, participants are on average willing to pay 6 to 17 cents more for the reminders.

To further explore how average WTP changes with the survey incentives, we construct Table 5. The table presents the average WTP of participants at each incentive level (using the median reported WTP for censored participants, as in our baseline specification) and shows how the average WTP changes with each $\$ 1$ increase in the incentive for completing the survey. The change in average WTP is significantly positive at each incentive level, and reaches its highest value $(\$ 0.22)$ when moving from the $\$ 3$ to the $\$ 4$ incentive.

\subsubsection{Robustness of incentive effects on WTP for reminders}

Because participants in our study are asked to value reminders for four different incentive levels, a potential concern is that anchoring bias might dampen the sensitivity of participants' WTP to reminders relative to what we would estimate in a pure between-subjects design. Table 6 examines this concern, leveraging the fact that we randomized the order in which participants faced the MPLs. Column (1) uses WTP data only from the first incentive level the participant was asked about, thus utilizing only between-subject variation. Column (2) uses data from the first two incentive levels. Column (3) uses data from the first three. Column (4) includes all data and thus replicates column (1) of Table 4. The coefficient on Incentive $(\$)$ increases as we move across the table, suggesting that as we add within-subject variation, participants appear to react more to the incentive level than when we consider the between-subject variation only. This result suggests that our within-subject variation may overstate the extent to which participants respond to the incentive when considering their WTP. As we will show below, this reinforces our result that participants undervalue the reminder technology. ${ }^{24}$

\subsubsection{The efficacy of the reminder technology}

As described in Section 4.1, we randomized 90\% of participants to either get or not get the reminder emails, regardless of their reported WTP. This randomization allows us to generate an estimate of the effect of the reminders on survey completion. In addition, since we independently randomized the incentive level for completing the survey, we can estimate the effect of reminders at each incentive level. ${ }^{25}$

Table 7 reports the probability that participants complete the survey when they received reminder emails and when they did not, restricting to these $90 \%$ of participants. The All

\footnotetext{
${ }^{24}$ Appendix Table C.2 shows the average WTP at each incentive level at each of the levels of restriction shown in Table 6.

${ }^{25}$ Appendix Table C.1 replicates Table 4 for the $90 \%$ of participants who either receive or do not receive the reminder emails based on random assignment. As one would expect from the fact that this $90 \%$ is randomly selected, estimates are nearly identical to those in Table 4.
} 
Randomized Reminders column shows that, across all incentive levels, $80 \%$ of participants who receive the reminder emails complete the survey, while only $43 \%$ of participants who do not receive the reminder emails do so. Consequently, the effect of reminders on survey completion is 37 percentage points, which is highly statistically significantly different from zero.

The other four columns of Table 7 show that the difference between the reminder and no reminder groups is large at each of the four incentive levels. The largest difference is 50 percentage points for the $\$ 2$ incentive group, driven by the fact that only $29 \%$ of participants complete the survey without the reminder emails when the incentive is $\$ 2$.

Table 7 also suggests two other interesting features of participant behavior. First, inattention appears to be the biggest factor in failure to complete the survey. The fraction of participants who do not complete the survey when they receive reminders ranges from $18 \%$ $21 \%$, which is significantly smaller than the $32-50$ percentage point effect of the reminders. Second, in the absence of reminders, participants appear to use their own reminder strategies more when the incentives are higher: financial incentives have a significant effect on completion of the survey in the absence of reminders, but they have a muted effect in the presence of reminders. This differential effect of financial incentives can be explained by our reminders and participants' own internal attention-increasing strategies being substitutes: participants are more likely to utilize their own attention-increasing strategies when the stakes are higher and they do not receive external reminders.

\subsubsection{Do participants invest optimally in reminder technology?}

Part 1 of Proposition 1 states that if participants are optimally investing in the reminder technology, then a $\$ 1$ increase in incentives for completing the survey should increase WTP for the reminder emails by $\$ 1$ times the increase in the likelihood of survey completion due to the reminder emails. Results from the prior sections allow us to directly make this comparison. Column (1) of Table 4 estimates that the WTP for the reminder emails increases by 15 cents for each $\$ 1$ increase in part 2 incentive (with a standard error of 1.1 cents). The All Participants column of Table 7 estimates that the reminder emails increased survey completion by 37 percentage points (with a standard error of 3.1 percentage points). These two estimates are highly statistically significantly different (Wald test, standard errors calculated using the delta method; $p<0.01$ ), which contradicts the first condition in Proposition 1. Comparing Table 5 to the last four columns of Table 7 further shows that the incremental change in average WTP at each incentive level is smaller than the effect of reminders on survey-completion at each incentive level. 


\subsection{Implications for under-planning}

The results of both of our studies show that individuals appear to under-value the attentionincreasing technologies they were offered. The results of our survey-completion study imply that individuals' WTP for the reminder technology was $0.15 / 0.37=41 \%$ as sensitive to the survey-completion incentives as the null of rational inattention would imply. In other words, individuals significantly under-appreciate how the implicit value of reminders increases when the stakes increase. Through the lens of the parametric model of overconfidence about one's attention described in Appendix A.3, this statistic can be interpreted to mean that participants think that their likelihood of being inattentive is only $\theta=0.41$ as high as it actually is.

Although not statistically significant, the results of Section 3.2.4 are qualitatively consistent with the results. The estimates in Section 3.2.4 imply that in week 1, weeks 1-4, and weeks 1-8 participants' demand for the reminder technology was, respectively, 0.025/0.038= $66 \%, 0.010 / 0.017=59 \%$, and $0.0065 / 0.0061=107 \%$ percent as sensitive to the task incentives as the null of full rationality would imply. Again, through the lens of the parametric model of overconfidence in Appendix A.3, these statistic imply that individuals think their likelihood of being inattentive to the survey task is $\theta=0.66, \theta=0.59$, or $\theta=1.07$ as high as it actually is. That participants appear to under-value plan making the most in the earlier weeks of the study is consistent with learning over time about the value of plan-making, although the standard errors are too large to draw this conclusion with reasonable certainty.

\section{Conclusion}

While a large and growing literature shows that attention-increasing interventions such as reminders and plan-making tools can have significant effects on economically important behaviors, this literature rarely asks the question of whether individuals value these tools rationally. This paper addresses this question with two theory-driven, quantitative tests. We find that individuals' demand for attention-increasing tools is qualitatively consistent with the predictions of rational inattention but is quantitatively inconsistent with the null of rationality. While this under-valuation may be context-dependent, our method can be ap-

plied more broadly to explore how individuals value attention-increasing technologies across various domains.

First, our methods are immediately portable to other settings where the impact of reminders and planning prompts has already been documented-e.g., medical compliance, savings, loan repayment, and voting (see footnote 1 for references). In many of these do- 
mains, the market already offers various attention enhancements (e.g., smart-caps on pill bottles), and thus our methods can help assess whether individuals value these products rationally, or whether take-up of these products needs to be encouraged. Some of these domains, like medical compliance, are additionally interesting because they feature repeated behaviors in a relatively stable environment and thus ample opportunities to learn. A key question for future research is whether individuals learn to appreciate the value of attention enhancements with more experience.

Second, our methodology could be used more broadly to test rational inattention models in the types of laboratory psychometric tasks traditionally used to quantify attention costs (e.g., Dean and Neligh, 2018; Ambuehl et al., 2018; Caplin et al., forthcominga). For example, one could test if participants' WTP to decrease the difficulty of a task is consistent with the full-rationality benchmark. In a controlled laboratory setting, researchers could also vary participants' experience with a given task to explore how perceptions of attention production functions change with experience.

Third, our methodology could be used to test whether people understand their production functions for attention-consuming tasks in field settings such as those of Dean (2019), Kaur et al. (2019), or Bessone et al. (2020). In these settings, avoiding noise and other distracting stimuli, or investing in sleep, constitute investments in reducing the cost of attention. In such settings, researchers could quantify how the willingness to pay for reductions in the cost of attention varies with the piece-rate for task completion.

More generally, our tests could be applied to any setting that involves domains of behavior that feature "intermediate" actions. For example, our methods could be used to quantify whether students fully understand the relationship between studying and test performance, whether individuals understand the link between education and earnings, or whether individuals properly invest in "good habits." 


\section{References}

Allcott, Hunt and Judd Kessler, "The Welfare Effects of Nudges: A Case Study of Energy Use Social Comparisons," American Economic Journal: Applied Economics, 2019, 11 (1), 236-276.

Altmann, Steffen and Christian Traxler, "Nudges at the Dentist," European Economic Review, 2014, 72, 19-38.

Ambuehl, Sandro, Axel Ockenfels, and Colin Stewart, "Attention and Selection Effects," working paper, 2018.

Augenblick, Ned, "Short-Term Discounting of Unpleasant Tasks," working paper, 2020.

_, Muriel Niederle, and Charles Sprenger, "Working over time: Dynamic inconsistency in real effort tasks," Quarterly Journal of Economics, 2015, 130 (3), 1067-1115.

Bartos, Vojtêch, Michal Bauer, Julie Chytilová, and Filip Matêjka, "Attention Discrimination: Theory and Field Experiments with Monitoring Information Acquisition," American Economic Review, June 2016, 106 (6), 1437-75.

Bessone, Pedro, Gautam Rao, Frank Schilbach, Heather Scofield, and Mattie Toma, "Sleepless in Chennai: The Consequences of Increasing Sleep among the Urban Poor," working paper, 2020.

Bronchetti, Erin Todd, David B. Huffman, and Ellen Magenheim, "Attention, intentions, and follow-through in preventive health behavior: Field experimental evidence on flu vaccination," Journal of Economic Behavior and Organization, 2015, 116, 270-291.

Butera, Luigi, Robert Metcalfe, William Morrison, and Dmitry Taubinsky, "The Deadweight Loss of Social Recognition," working paper, 2019.

Cadena, Ximena and Antoinette Schoar, "Remembering to Pay? Reminders vs. Financial Incentives for Loan Payments," working paper, 2011.

Calzolari, Giacomo and Mattia Nardotto, "Effective Reminders," Management Science, 2017, 63 (9), 2915-2932.

Caplin, Andrew, "Measuring and Modeling Attention," Annual Review of Economics, 2016, 8 (1), 379-403.

- and Mark Dean, "Revealed Preference, Rational Inattention, and Costly Information Acquisition," American Economic Review, July 2015, 105 (7), 2183-2203.

_, Daniel Csaba, John Leahy, and Oded Nov, "Rational Inattention, Competitive Supply, and Psychometrics," Quarterly Journal of Economics, forthcoming.

_ , Mark Dean, and John Leahy, "Rational Inattention, Optimal Consideration Sets, and Stochastic Choice," Review of Economic Studies, forthcoming. 
Carrera, Mariana, Heather Royer, Mark Stehr, Justin Sydnor, and Dmitry Taubinsky, "The Limits of Simple Implementation Intentions: Evidence from a Field Experiment on Making Plans to Exercise," Journal of Health Economics, 2018, 62, 95104.

Carvalho, Leandro and Dan Silverman, "Complexity and Sophistication," working paper, 2019.

Castleman, Benjamin L. and Lindsay C. Page, "Freshman Year Financial Aid Nudges: An Experiment to Increase FAFSA Renewal and College Persistence," Journal of Human Resources, 2016, 51 (2), 389-415.

Damgaard, Mette Trier and Christina Gravert, "The hidden costs of nudging: Experimental evidence from reminders in fundraising," Journal of Public Economics, 2018, $15 \%, 15-26$.

_ and Helena Skyt Nielsen, "Nudging in education," Economics of Education Review, 2018, 64 (313-342).

Dean, Joshua T., "Noise, Cognitive Function and Worker Productivity," working paper, 2019.

Dean, Mark and Nathaniel Neligh, "Experimental Tests of Rational Inattention," working paper, 2018.

Ericson, Keith, "Forgetting We Forget: Overconfidence and Memory," Journal of the European Economic Association, 2011, 9 (1), 867-875.

_ , "On the Interaction of Memory and Procsastination: Implications for Reminders, Deadlines, and Empirical Estimation," Journal of the European Economic Assocation, 2017, 15 (4), 692-729.

Gabaix, Xavier, "Behavioral Inattention," in Douglas Bernheim, Stefano DellaVigna, and David Laibson, eds., Handbook of Behavioral Economics, Vol. 2, Elsevier, 2019.

_ , David Laibson, Guillermo Moloche, and Stephen Weinberg, "Costly Information Acquisition: Experimental Analysis of a Boundedly Rational Model," American Economic Review, 2006, 96, 1043-1068.

Gollwitzer, Peter M. and Paschal Sheeran, "Implementation Intentions and Goal Achievement: A Meta-analysis of Effects and Processes," Advances in Experimental Social Psychology, 2006, 38, 69-119.

Hanna, Rema, Sendhil Mullainathan, and Joshua Schwartzstein, "Learning Through Noticing: Theory and Evidence from a Field Experiment," Quarterly Journal of Economics, 2014, 129 (3), 1311-1353.

Karlan, Dean, Margaret McConnell, Sendhil Mullainathan, and Jonathan Zinman, "Getting to the Top of Mind: How Reminders Increase Saving," Management Science, 2016, 62 (12), 3393-3411. 
Kaur, Supreet, Sendhil Mullainathan, Suanna Oh, and Frank Schilbach, "Does Financial Strain Lower Productivity?," working paper, 2019.

Levitt, Steven D., John A. List, Susanne Neckermann, and Sally Sadoff, "The Behavioralist Goes to School: Leveraging Behavioral Economics to Improve Educational Performance," American Economic Journal: Economic Policy, 2016, 8 (4), 183-219.

Maćkowiak, Bartosz, Filip Matêjka, and Mirko Wiederholt, "Rational Inattention: A Disciplined Behavioral Model," Working Paper May 2018.

Martin, Daniel, "Rational Inattention in Games: Experimental Evidence," working paper, 2016.

Marx, Benjamin M. and Lesley J. Turner, "Student Loan Nudges: Experimental Evidence on Borrowing and Educational Attainment," American Economic Journal: Economic Policy, 2019, 11 (2), 108-141.

Matejka, Filip and Alisdair McKay, "Rational Inattention to Discrete Choices: A New Foundation for the Multinomial Logit Model," American Economic Review, January 2015, $105(1), 272-298$.

Milkman, Katherine L., John Beshears, James Choi, David Laibson, and Brigitte C. Madrian, "Planning prompts as a means of increasing preventive screening rates," Preventive Medicine, 2013, 56 (1), 92-93.

_, _, James J. Choi, David Laibson, and Brigitte C. Madrian, "Using implementation intentions prompts to enhance influenza vaccination rates," Proceedings of the National Academy of Sciences, 2011, 108 (26), 10415-10420.

Mullainathan, Sendhil, "A Memory-Based Model of Bounded Rationality," Quarterly Journal of Economics, 2002, 117 (3), 735-774.

Nafziger, Julia, "Spillover Effects of Nudges," Economics Letters, forthcoming.

Nickerson, David W. and Todd Rogers, "Do You Have a Voting Plan? Implementation Intentions, Voter Turnout, and Organic Plan Making," Psychological Science, 2010, 21 (2), 194-199.

Oreopoulos, Philip, Richard W. Patterson, Uros Petronijevic, and Nolan G. Pope, "When Studying and Nudging Don't Go as Planned: Unsuccessful Attempts to Help Traditional and Online College Students," Journal of Human Resources, forthcoming.

Rogers, Todd, Katherine L. Milkman, Leslie K. John, and Michael I Norton, "Beyond good intentions: Prompting people to make plans improves follow-through on important tasks," Behavioral Science and Policy, 2015, 1 (2).

Sims, Christopher A., "Implications of Rational Inattention," Journal of Monetary Economics, 2003, 50 (3), $665-690$. 
Tasoff, Joshua and Robert Letzler, "Everyone believes in redemption: Nudges and overoptimism in costly task completion," Journal of Economic Behavior and Organization, 2014, 107, 107-122.

Taubinsky, Dmitry, "From Intentions to Actions: A Model and Experimental Evidence of Inattentive Choice," working paper, 2014. 
Figure 1: Illustration of Proposition 1

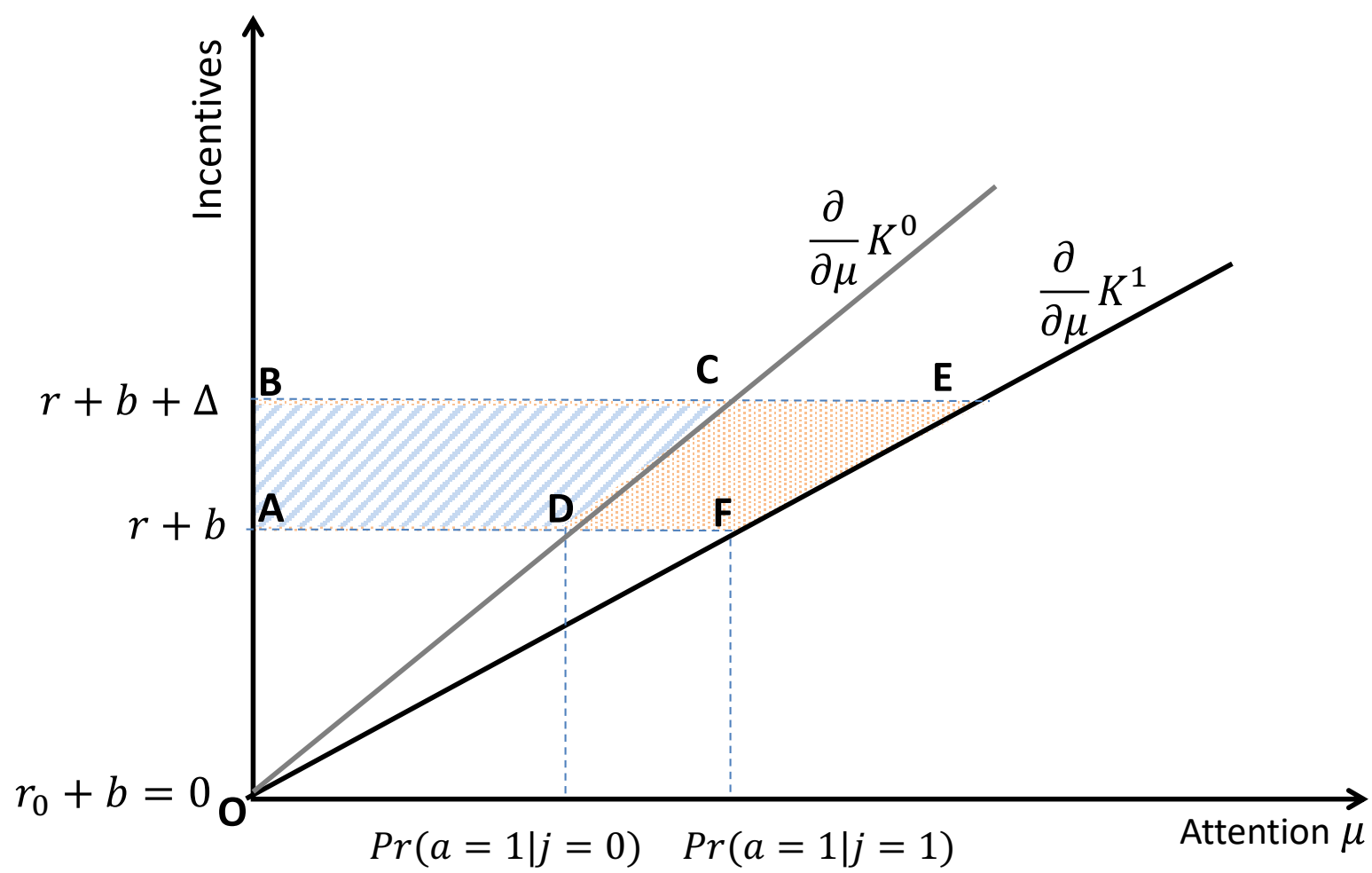

The figure illustrates equation (1) of Proposition 1. The top line plots the marginal costs of attention under technology $j=0$, while the bottom line plots marginal costs under technology $j=1$. The area DCEF corresponds to the change in WTP for technology $j=1$ over $j=0$ when the financial incentive is increase from $r$ to $r+\Delta$. 
Figure 2: Online Education Experiment Control Group Means (Week-by-Week)

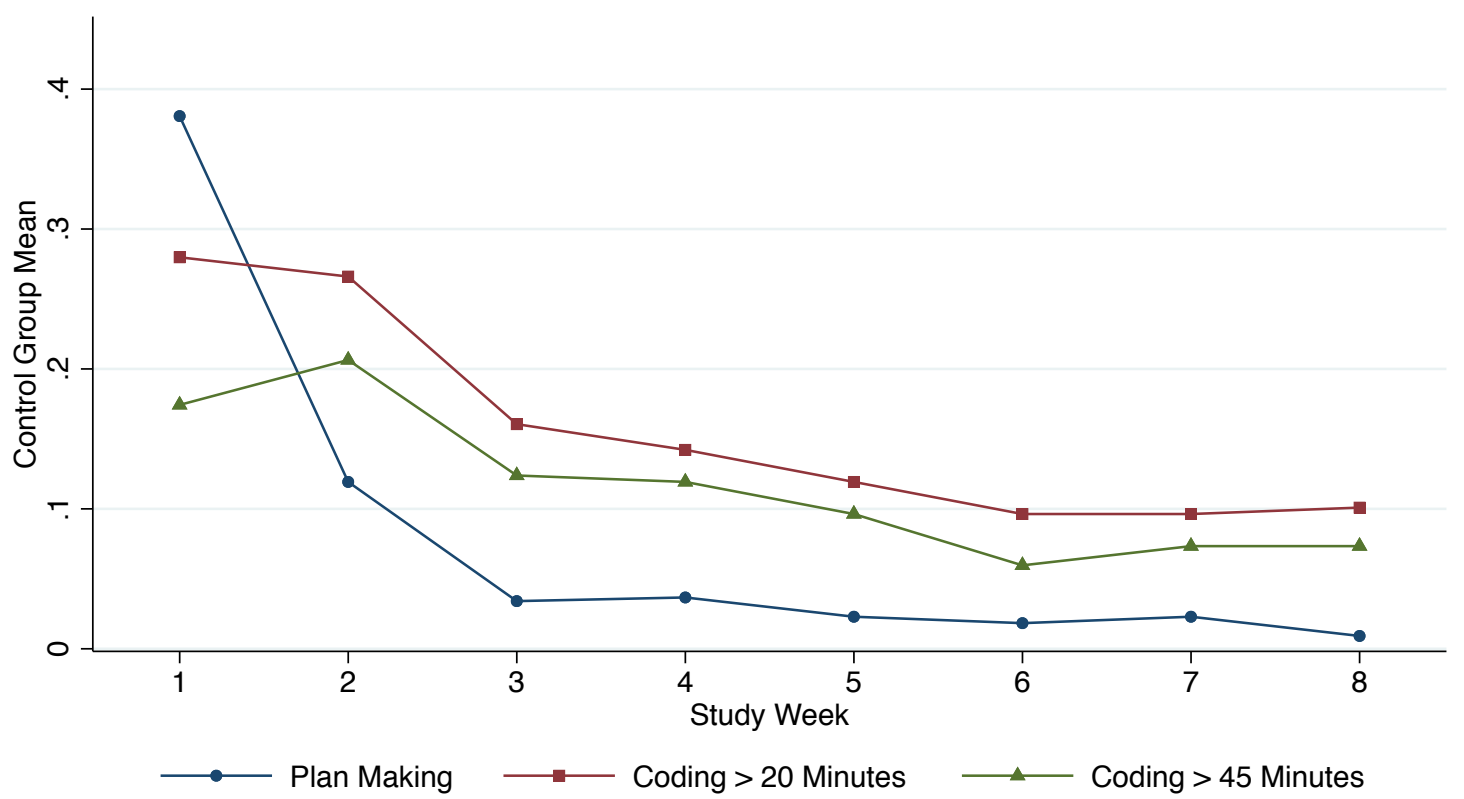

This figure shows control group means for plan making and completing at least 20 minutes or at least 45 minutes of the coding course for each week of the study. 
Figure 3: The Effect of Incentives on Plan Making and Coding Task Completion A. The Effect of Incentives on Plan Making

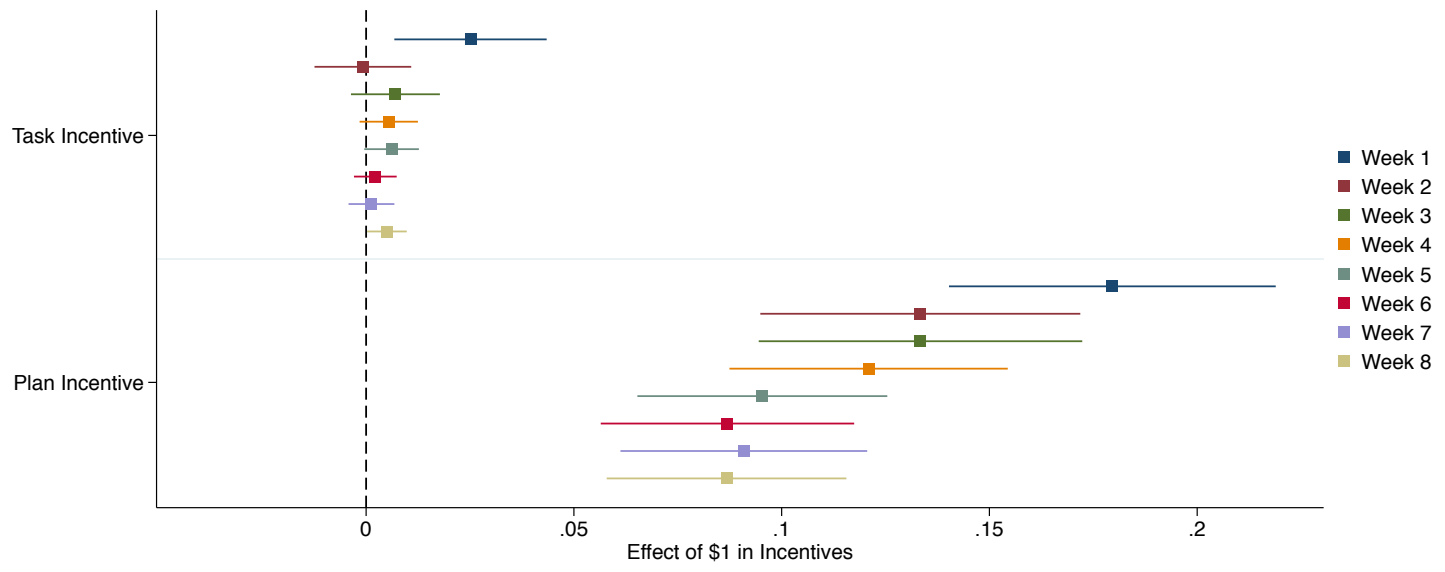

B. The Effect of Incentives on Coding Task Completion (>20 Minutes)

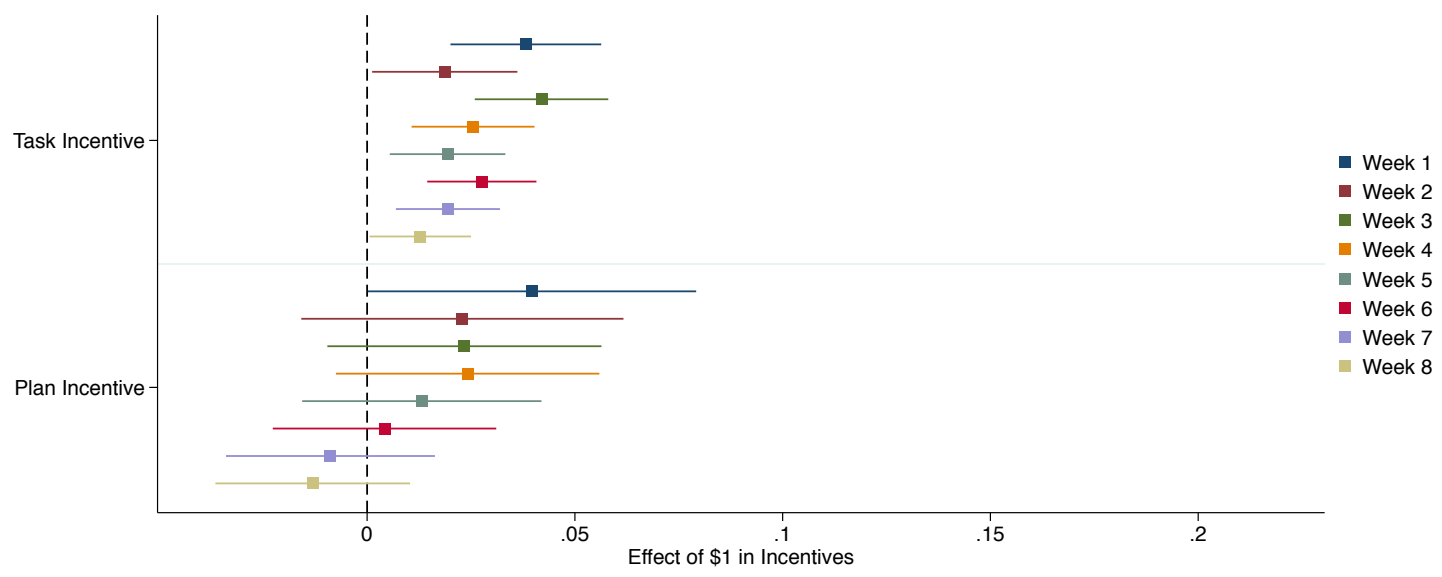

C. The Effect of Incentives on Coding Task Completion (>45 Minutes)

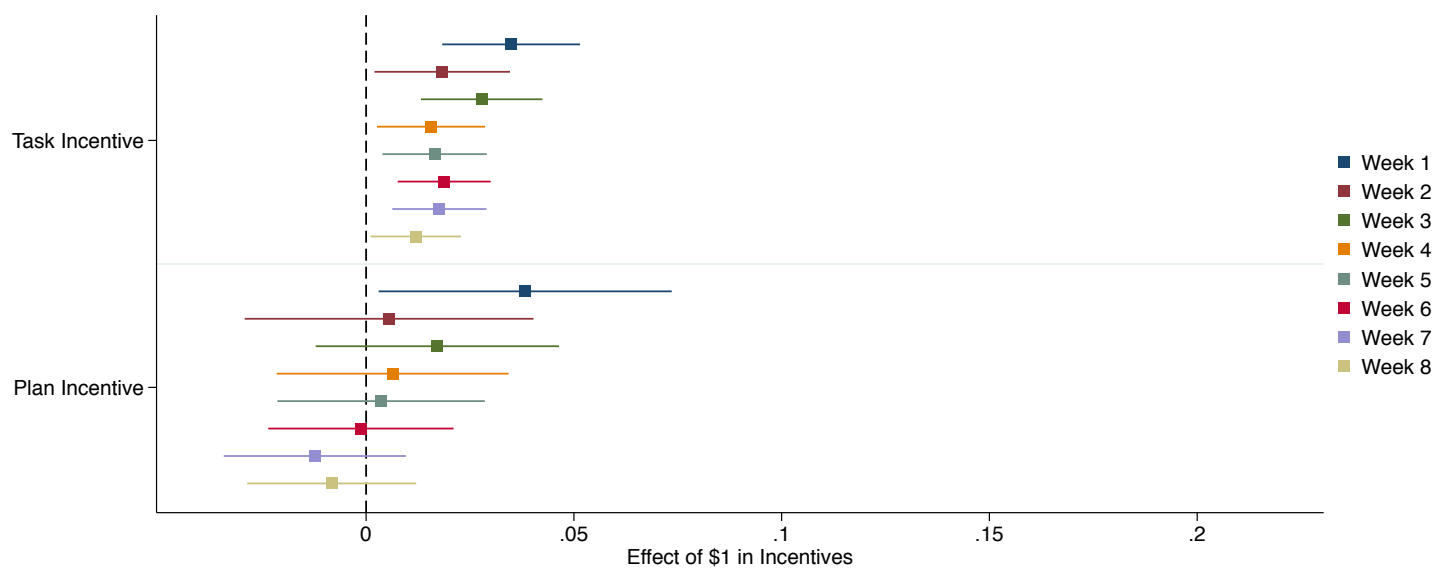

This figure shows estimates for the effect of incentives on plan making and coding task completion for each week of the study. We use "Task Incentive" as shorthand for coding-task incentive and "Plan Incentive" for plan-making incentive. Panel A shows estimates of the effect of incentives on whether or not participants made a plan. Panel B shows the effect of incentives on completing at least 20 minutes of coding during the week. Panel $\mathrm{C}$ shows the effect of incentives on completing at least 45 minutes of coding during the week. Whiskers report $95 \%$ confidence intervals around each estimate. 
Figure 4: CDFs of WTP for the Reminder Emails

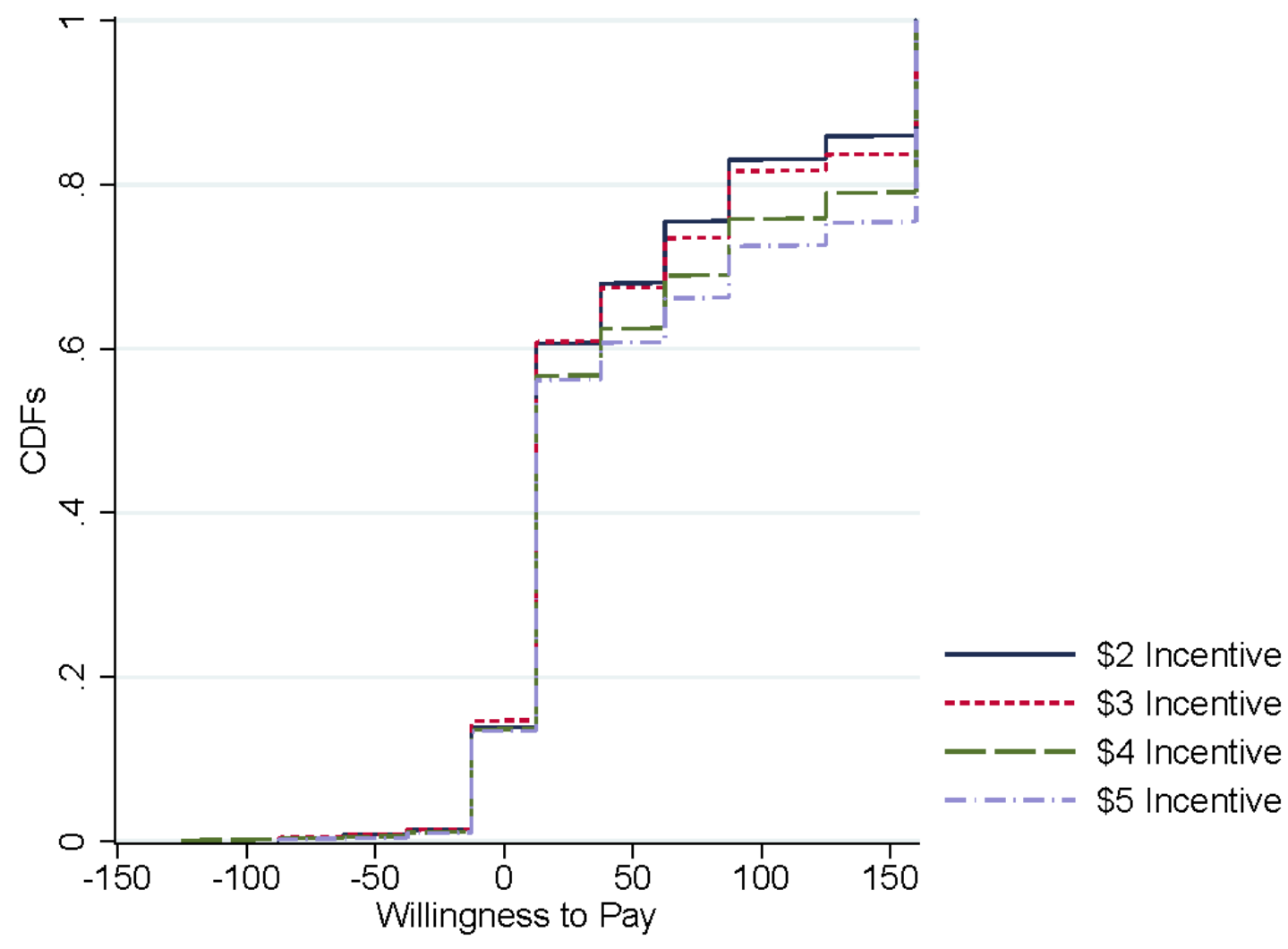

This figure shows CDFs of the willingness to pay (WTP), in cents, for the set of three reminder emails. There is a CDF for each possible incentive for completing the survey. While the CDFs look rather identical in the negative WTP region, the CDFs indicate higher willingness to pay when the incentives for completing the survey increase. 
Table 1: Participant Characteristics (Experiment 1)

\begin{tabular}{lcll}
\hline \multicolumn{1}{c}{ Students } & \multicolumn{3}{c}{ Alumni } \\
\hline First-year & 0.28 & 2017 & 0.22 \\
& $(0.45)$ & & $(0.41)$ \\
Sophomore & 0.22 & 2016 & 0.18 \\
& $(0.41)$ & & $(0.39)$ \\
Junior & 0.23 & 2015 & 0.21 \\
& $(0.42)$ & & $(0.41)$ \\
Senior & 0.28 & 2014 & 0.19 \\
& $(0.45)$ & & $(0.39)$ \\
& & 2013 & 0.20 \\
& & & $(0.40)$ \\
Female & 0.65 & Female & 0.70 \\
& $(0.48)$ & & $(0.46)$ \\
Male & 0.31 & Male & 0.27 \\
& $(0.46)$ & & $(0.44)$ \\
Non-binary or no answer & 0.04 & Non-binary or no answer & 0.03 \\
& $(0.20)$ & & $(0.21)$ \\
N & 686 & N & 687 \\
\hline
\end{tabular}

This table presents summary statistics for the participants in experiment 1, split between student and alumni groups. The Pay-to-Code sample includes 496 participants divided between $\$ 2$ and $\$ 5$ incentive arms. The Pay-to-Plan sample includes 487 participants divided between $\$ 1$ and $\$ 2$ incentive arms. The remaining participants include 218 control participants and 172 participants assigned to the Combination treatment of $\$ 1$ plan-making incentives and $\$ 2$ coding-task incentives. 
Table 2: The Effect of Plan-Making Incentives on Plan Making and Coding Task Completion Panel A: The Effect on Plan Making (First Stage)

\begin{tabular}{lccc}
\hline & $(1)$ & $(2)$ & $(3)$ \\
& Week 1 & Weeks 1-4 & Weeks 1-8 \\
\hline Plan Incentive & $\begin{array}{c}0.180^{* * *} \\
(0.020)\end{array}$ & $\begin{array}{c}0.142^{* * *} \\
(0.014)\end{array}$ & $\begin{array}{c}0.116^{* * *} \\
(0.013)\end{array}$ \\
\hline Obs. & 705 & 705 & 705 \\
$\mathrm{R}^{2}$ & 0.137 & 0.163 & 0.131 \\
Control Mean & 0.381 & 0.150 & 0.082 \\
Controls & Yes & Yes & Yes \\
Campus FE & Yes & Yes & Yes \\
\hline
\end{tabular}

Panel B: The Effect on Coding Task Completion (Reduced Form)

\begin{tabular}{lcccccc}
\hline & $(1)$ & $(2)$ & $(3)$ & $(4)$ & $(5)$ & $(6)$ \\
& $>20(1)$ & $>20(1-4)$ & $>20(1-8)$ & $>45(1)$ & $>45(1-4)$ & $>45(1-8)$ \\
\hline Plan Incentive & $0.040^{* *}$ & $0.028^{* *}$ & 0.013 & $0.038^{* *}$ & 0.017 & 0.006 \\
& $(0.020)$ & $(0.013)$ & $(0.011)$ & $(0.018)$ & $(0.012)$ & $(0.009)$ \\
\hline Obs. & 705 & 705 & 705 & 705 & 705 & 705 \\
$\mathrm{R}^{2}$ & 0.057 & 0.049 & 0.051 & 0.036 & 0.035 & 0.041 \\
Control Mean & 0.280 & 0.212 & 0.158 & 0.174 & 0.156 & 0.116 \\
Controls & Yes & Yes & Yes & Yes & Yes & Yes \\
Campus FE & Yes & Yes & Yes & Yes & Yes & Yes \\
\hline
\end{tabular}

Panel C: The Effect of Plan Making on Coding Task Completion (IV)

\begin{tabular}{lcccccc}
\hline & $(1)$ & $(2)$ & $(3)$ & $(4)$ & $(5)$ & $(6)$ \\
& $>20(1)$ & $>20(1-4)$ & $>20(1-8)$ & $>45(1)$ & $>45(1-4)$ & $>45(1-8)$ \\
\hline Plan Making & $0.221^{* *}$ & $0.194^{* *}$ & 0.114 & $0.213^{* *}$ & 0.118 & 0.053 \\
& $(0.105)$ & $(0.087)$ & $(0.086)$ & $(0.096)$ & $(0.076)$ & $(0.074)$ \\
\hline Obs. & 705 & 705 & 705 & 705 & 705 & 705 \\
$\mathrm{R}^{2}$ & 0.147 & 0.174 & 0.133 & 0.092 & 0.120 & 0.085 \\
Control Mean & 0.280 & 0.212 & 0.158 & 0.174 & 0.156 & 0.116 \\
Controls & Yes & Yes & Yes & Yes & Yes & Yes \\
Campus FE & Yes & Yes & Yes & Yes & Yes & Yes \\
\hline
\end{tabular}

This table estimates the effect of plan-making incentives on plan making and coding task completion. We use "Plan Incentive" as shorthand for plan-making incentive (in dollars). Panel A shows the effect of plan-making incentives on whether experimental participants made a plan. Column (1) shows the effect of plan-making incentives in the first week of the experiment. Column (2) shows the average effect for the first four weeks. Column (3) shows the average effect for the entire experiment. Panel B shows the effect of plan-making incentives on coding task completion. Columns (1-3) show the effect on an indicator variable for whether or not the participant worked on the coding task for more than 20 minutes: Column (1) estimates the effect over the first week, Column (2) over the first four weeks, and Column (3) over the entire experiment. Columns (4-6) show analogous estimates, but for an indicator variable for whether or not the participant worked on the coding task for more than 45 minutes each week. Panel C shows the 2SLS estimates instrumenting for whether participants made a plan using the plan-making incentive as an instrument. The dependent variables are the same as in Panel B. Standard errors are shown in parentheses. ${ }^{*} p<0.1,{ }^{* *} p<0.05,{ }^{* * *} p<0.01$. 
Table 3: The Effect of Coding-Task Incentives on Plan Making and Coding Task Completion Panel A: The Effect on Plan Making

\begin{tabular}{lccc}
\hline & $(1)$ & $(2)$ & $(3)$ \\
& Week 1 & Weeks 1-4 & Weeks 1-8 \\
\hline Task Incentive & $0.025^{* * *}$ & $0.010^{* *}$ & $0.007^{* *}$ \\
& $(0.009)$ & $(0.004)$ & $(0.003)$ \\
\hline Obs. & 714 & 714 & 714 \\
$\mathrm{R}^{2}$ & 0.050 & 0.058 & 0.049 \\
Control Mean & 0.381 & 0.150 & 0.082 \\
Controls & Yes & Yes & Yes \\
Campus FE & Yes & Yes & Yes \\
\hline
\end{tabular}

Panel B: The Effect on Coding Task Completion

\begin{tabular}{lcccccc}
\hline & $(1)$ & $(2)$ & $(3)$ & $(4)$ & $(5)$ & $(6)$ \\
& $>20(1)$ & $>20(1-4)$ & $>20(1-8)$ & $>45(1)$ & $>45(1-4)$ & $>45(1-8)$ \\
\hline Task Incentive & $0.038^{* * *}$ & $0.031^{* * *}$ & $0.025^{* * *}$ & $0.035^{* * *}$ & $0.024^{* * *}$ & $0.020^{* * *}$ \\
& $(0.009)$ & $(0.006)$ & $(0.005)$ & $(0.008)$ & $(0.006)$ & $(0.005)$ \\
\hline Obs. & 714 & 714 & 714 & 714 & 714 & 714 \\
$\mathrm{R}^{2}$ & 0.043 & 0.059 & 0.069 & 0.041 & 0.057 & 0.075 \\
Control Mean & 0.280 & 0.212 & 0.158 & 0.174 & 0.156 & 0.116 \\
Controls & Yes & Yes & Yes & Yes & Yes & Yes \\
Campus FE & Yes & Yes & Yes & Yes & Yes & Yes \\
\hline
\end{tabular}

This table shows estimates for the effect of coding-task incentives on plan making and coding task completion. We use "Task Incentive" as shorthand for coding-task incentive (in dollars). Panel A shows estimates of the effect of coding-task incentives on whether or not participants made a plan. Column (1) shows the effect of coding-task incentives in the first week of the experiment. Column (2) shows the average effect over the first four weeks. Column (3) shows the effect over the entire experiment. Panel B shows the effect of coding-task incentives on coding task completion. Columns (1-3) show the effect on an indicator variable for whether or not the participant worked on the coding task for more than 20 minutes: Column (1) estimates the effect over the first week, Column (2) over the first four weeks, and Column (3) over the entire experiment. Columns (4-6) show analogous estimates, but for an indicator variable for whether or not the participant worked on the coding task for more than 45 minutes each week. Standard errors are shown in parentheses. ${ }^{*} p<0.1,{ }^{* *} p<0.05,{ }^{* * *} p<0.01$. 
Table 4: Willingness to Pay for Reminders

\begin{tabular}{lcccc}
\hline & $(1)$ & $(2)$ & $(3)$ & $(4)$ \\
& OLS & OLS & OLS & Tobit \\
& WTP $(\$)$ & WTP $(\$)$ & WTP $(\$)$ & WTP $(\$)$ \\
\hline Incentive $(\$)$ & $0.15^{* * *}$ & $0.17^{* * *}$ & $0.17^{* * *}$ & $0.06^{* * *}$ \\
& $(0.011)$ & $(0.024)$ & $(0.020)$ & $(0.006)$ \\
\hline Observations & 3776 & 3775 & 3776 & 3776 \\
Number of Participants & 944 & 944 & 944 & 944 \\
Participant FE & Yes & Yes & Yes & No \\
Mean WTP, \$2 Incentive & 0.49 & 0.58 & 0.92 & 0.42 \\
Censoring Specification & Median Survey & Survey Resp. & $\$ 5$ Top & Tobit \\
\hline
\end{tabular}

This table presents estimates of how individual's willingness to pay (WTP) for reminders varies with incentives. The columns vary how they treat censored responses-i.e., responses that were at the boundary of the multiple price list presented to participants. In Column (1), we replace a participant's WTP if they are top-censored with the median reported WTP from an unincentivized survey question among all top-censored participants within a particular incentive level. In Column (2), we replace this value with the participant's own reported WTP from that unincentivized survey question. In Column (3), we replace this value with $\$ 5.00$. In Column (4), we estimate the regression using a Tobit estimator. Values are represented in dollars. The number of observations falls by one in Column (2) because one participant did not complete one of the survey questions. Standard errors, clustered by participant, are shown in parentheses. ${ }^{*} p<0.1,{ }^{* *} p<0.05,{ }^{* * *} p<0.01$.

Table 5: Willingness to Pay for Reminders by Survey Completion Incentive

\begin{tabular}{lllll}
\hline Mean WTP & \$2 Incentive & \$3 Incentive & \$4 Incentive & \$5 Incentive \\
& 0.49 & 0.60 & 0.82 & 0.91 \\
& $(0.022)$ & $(0.029)$ & $(0.038)$ & $(0.040)$ \\
Difference in WTP & & & \\
& & \$3 Incentive & \$4 Incentive & \$5 Incentive \\
& $-\$ 2$ Incentive & - \$3 Incentive & - \$4 Incentive \\
& 0.11 & 0.22 & 0.09 \\
& $(0.037)$ & $(0.048)$ & $(0.055)$ \\
\hline
\end{tabular}

Notes: This table presents mean willingness to pay (WTP) for the reminder, and how it changes with the incentive for completing the survey. The top row presents the mean WTP in each incentive condition. The second row presents how the WTP increases from one incentive condition to the next. The censored responses are as in column (1) of Table 4: we replace a participant's WTP if they are top-censored with the median reported WTP from an unincentivized survey question among all top-censored participants within a particular incentive level. Standard errors are shown in parentheses. 
Table 6: Willingness to Pay for Reminders: Order Effects

\begin{tabular}{|c|c|c|c|c|}
\hline & $\begin{array}{c}(1) \\
\text { OLS } \\
\text { 1st Incentive }\end{array}$ & $\begin{array}{c}(2) \\
\text { OLS } \\
\text { 1st and 2nd Incentive }\end{array}$ & $\begin{array}{c}(3) \\
\text { OLS } \\
\text { 1st-3rd Incentive }\end{array}$ & $\begin{array}{c}(4) \\
\text { OLS } \\
\text { All Incentives }\end{array}$ \\
\hline Incentive $(\$)$ & $\begin{array}{l}0.09 * * * \\
(0.029)\end{array}$ & $\begin{array}{c}0.12^{* * *} \\
(0.017)\end{array}$ & $\begin{array}{l}0.13^{* * *} \\
(0.012)\end{array}$ & $\begin{array}{l}0.15^{* * *} \\
(0.011)\end{array}$ \\
\hline Observations & 944 & 1888 & 2832 & 3776 \\
\hline Participant FE & No & Yes & Yes & Yes \\
\hline Mean WTP, \$2 Incentive & 0.61 & 0.59 & 0.59 & 0.58 \\
\hline Censoring Specification & Median Survey & Median Survey & Median Survey & Median Survey \\
\hline
\end{tabular}

This table presents estimates of how individual's willingness to pay (WTP) for reminders varies with incentives, by whether the WTP for reminders elicitation includes only the first elicitation (column 1), the first and second elicitations (column 2), the first through third elicitations (column 3), or all four elicitations (column 4). The censored responses are treated as in column (1) of Table 4: we replace a participant's WTP if they are top-censored with the median reported WTP from an unincentivized survey question among all top-censored participants within a particular incentive level. Standard errors, clustered by participant, are shown in parentheses. ${ }^{*} p<0.1,{ }^{* *} p<0.05,{ }^{* * *} p<0.01$.

Table 7: Completion Rates by Incentive Size and Reminder Group

\begin{tabular}{lccccc}
\hline Experimental Group & All Participants & $\$ 2$ Incentive & $\$ 3$ Incentive & \$4 Incentive & \$5 Incentive \\
Reminder & 0.80 & 0.79 & 0.79 & 0.82 & 0.80 \\
No Reminder & 0.43 & 0.29 & 0.47 & 0.47 & 0.47 \\
& & & & & 0.35 \\
Difference & 0.37 & 0.50 & 0.32 & 0.33 \\
Number of Participants & $(0.031)^{* * *}$ & $(0.060)^{* * *}$ & $(0.065)^{* * *}$ & $(0.060)^{* * *}$ & $(0.061)^{* * *}$ \\
& 847 & 208 & 199 & 223 & 217 \\
\hline
\end{tabular}

This table presents survey completion rates for different incentive sizes and reminder groups. The "Reminder" and "No Reminder" rows present completion rates for the group that randomly received the reminders and the group that randomly did not. Results are shown by incentive level and for all incentive levels pooled together. The "Difference" row shows the difference between the reminder experimental group and the no reminder group. Standard errors for the difference are shown in parentheses. ${ }^{*} p<0.1,{ }^{* *} p<0.05,{ }^{* * *} p<0.01$. The final row shows the number of participants in the pooled sample and in each incentive level. 


\section{Appendices (not for publication)}

\section{A Mathematical appendix}

\section{A.1 Further discussion of the framework}

We extend the model such that $b_{i}$ is draw from some distribution $G_{i}$, and is realized only in the future when the individual has an opportunity to choose $a=0$. Our only assumption is that $G_{i}(\cdot)$ has a continuous density function for each $i$, and that $G_{i}(x)$ is smoothly distributed for each $x$.

In period 2 , individuals are attentive with probability $\mu$. If individuals are inattentive they default to $a=0$. If individuals are attentive, they choose whether or not to complete the task, with action $a=1$ denoting completion and $a=0$ denoting not completion. The benefits of choosing $a=1$ over $a=0$ are value $r+b$, where $b>0$ is the intrinsic benefits and $r$ is the observable pecuniary incentive. We assume that $b$ is drawn from some distribution $G_{i}$ that is independent of $\eta$. Thus, with some abuse of notation, we sometimes denote this distribution by $G_{\omega}$. Individuals only know $G_{i}$ in period 1 . They learn the realization $b$ in period 2 only (if they are attentive).

Given an attention technology $j$, the net utility benefit of an attention level $\mu$ is therefore

$$
\mu B_{i}(r)-K_{i}^{j}(\mu)
$$

where

$$
B_{i}(r):=\int_{b+r>0}(b+r) d G_{i}(b)
$$

Under the assumption that utility is locally linear in the pecuniary incentives, rationally inattentive individuals choose $j$ and $\mu$ to maximize

$$
U_{i}(j, \mu \mid p, r)=\mu \int_{x+r>0}(x+r) d G_{i}(x)-K_{i}^{j}(\mu)-p j
$$

Define the indirect utility functions

$$
\begin{aligned}
& M_{i}^{1}(r):=\max _{\mu}\left\{\mu \int_{x+r>0}(x+r) d G_{i}(x)-K_{i}^{j}(\mu)\right\} \\
& \left.M_{i}^{0}(r):=\max _{\mu}\left\{\mu \int_{x+r>0}(x+r) d G_{i}(x)-K_{i}^{0}(\mu)\right)\right\}
\end{aligned}
$$


Our main assumption is:

Assumption A. $M_{i}^{1}(r)$ and $M_{i}^{1}(r)-M_{i}^{0}(r)$ are smoothly distributed in $i$ for each $r$.

As one example under which this assumption holds, suppose that types can be partitioned into three-dimensional types $i=\left(\omega, \eta^{1}, \eta^{2}\right)$, and that $K_{i}^{j}=K_{\omega}^{j}+\eta^{j}$ where $\eta^{j}$ is a random variable on $\mathbb{R}$ that possesses a continuous density function, and that is independent of $G_{i}(b)$. In this case, $\eta^{j}$ corresponds to the nuisance cost associated with choosing technology $j$. As another example, suppose that $K_{i}^{0}=K_{\omega}^{0}$ and $K_{i}^{1}=\eta K_{\omega}$, where $\eta$ is random variable on $\mathbb{R}^{+}$ that is independent of $G_{i}(b)$. Here, the interpretation is that $\eta$ captures individual differences in the extent to which $j=1$ reduces the marginal costs of attention.

\section{A.2 Proof of Proposition 1 under more general assumptions}

\section{Proof of part 1}

Proof. Individuals who maximize the function in (5) choose technology $j=1$ iff $p \leq$ $M_{i}^{1}(r)-M_{i}^{0}(r)$. Individual $i$ 's WTP for technology $j=1$ is thus $W_{i}(r):=M_{i}^{1}(r)-M_{i}^{0}(r)$. Assumption A implies that $W_{i}$ is differentiable almost everywhere. Let $\mu_{i}^{j}$ denote individual $i$ 's optimal choice of $\mu$ given technology $j$. Repeatedly applying the Envelope Theorem thus implies that

$$
\begin{aligned}
\frac{d}{d r} \mathbb{E}\left[W_{i}(r)\right] & =\mathbb{E}\left[\frac{d}{d r} M_{i}^{1}(r)\right]-\mathbb{E}\left[\frac{d}{d r} M_{i}^{0}(r)\right] \\
& =\mathbb{E}\left[\mu_{i}^{1} \cdot\left(1-G_{i}(-r)\right)\right]-\mathbb{E}\left[\mu_{i}^{0} \cdot\left(1-G_{i}(-r)\right)\right] \\
& =\operatorname{Pr}(a=1 \mid j=1, r)-\operatorname{Pr}(a=1 \mid j=0, r)
\end{aligned}
$$

where the expectations are taken over all $i$ for which $\frac{d}{d r} M_{i}^{1}(r)$ and $\frac{d}{d r} M_{i}^{0}(r)$ exist.

\section{Proof of part 2}

Proof. Define

$$
V_{i}(p, r)=\max _{j, \mu} U_{i}(j, \mu \mid p, r)
$$

Assumption A implies that $V_{i}$ is differentiable almost everywhere in $p$ and $r$, and thus repeated application of the Envelope Theorem implies that 


$$
\begin{aligned}
\frac{d}{d p} \frac{d}{d r} \mathbb{E}\left[V_{i}(p, r)\right] & =\frac{d}{d p} \mathbb{E}\left[\frac{d}{d r} V_{i}(p, r)\right] \\
& =\frac{d}{d p}\left[\operatorname{Pr}(j=1 \mid p, r) \mathbb{E}\left[\frac{d}{d r} M_{i}^{1}(r)\right]+\operatorname{Pr}(j=1 \mid p, r) \mathbb{E} \mathbb{E}\left[\frac{d}{d r} M_{i}^{0}(r)\right]\right] \\
& =\frac{d}{d p}\left[\operatorname{Pr}(j=1 \mid p, r) \mathbb{E}\left[\mu_{i}^{1} \cdot\left(1-G_{i}(-r)\right)\right]+\operatorname{Pr}(j=0 \mid p, r) \mathbb{E}\left[\mu_{i}^{0} \cdot\left(1-G_{i}(-r)\right)\right]\right] \\
& =\frac{d}{d p}[\operatorname{Pr}(j=1 \mid p, r) \operatorname{Pr}(a=1 \mid j=1, r)+\operatorname{Pr}(j=0 \mid p, r) \operatorname{Pr}(a=1 \mid j=0, r)] \\
& =\frac{d}{d p} \operatorname{Pr}(a=1 \mid p, r)
\end{aligned}
$$

where the expectations are taken over all $i$ for which $\frac{d}{d r} M_{i}^{1}(r)$ and $\frac{d}{d r} M_{i}^{0}(r)$ exist.

Similarly,

$$
\begin{aligned}
\frac{d}{d r} \frac{d}{d p} \mathbb{E}\left[V_{i}(p, r)\right] & =\frac{d}{d r} \mathbb{E}\left[\frac{d}{d p} V_{i}(p, r)\right] \\
& =-\frac{d}{d r} \operatorname{Pr}(j=1 \mid p, r)
\end{aligned}
$$

where the expectation is taken over all $i$ for which $\frac{d}{d r} M_{i}^{1}(r)$ and $\frac{d}{d r} M_{i}^{0}(r)$ exist.

Since $\frac{d}{d p} \frac{d}{d r} \mathbb{E}\left[V_{i}(p, r)\right]=\frac{d}{d r} \frac{d}{d p} \mathbb{E}\left[V_{i}(p, r)\right]$, the result follows.

\section{A.3 A parametric model of overconfidence about future attentive- ness}

Suppose that consumers are overconfident about being attentive to the activity in the future. In particular, when in reality they are inattentive with probability $1-\mu$, they think they will be inattentive with probability $\theta(1-\mu)$, where $\theta<1$. Equivalently, individuals' perceived attentiveness is $\hat{\mu}=(1-\theta)+\theta \mu$. Let $\hat{\mu}_{i}^{j}$ be individual $i$ 's perceived attentiveness if they have technology $j$.

Extending equation (9),

$$
\begin{aligned}
\frac{d}{d r} W_{i}(r) & =\mathbb{E}\left[\hat{\mu}_{i}^{1} \cdot\left(1-G_{i}(-r)\right)\right]-\mathbb{E}\left[\hat{\mu}_{i}^{0} \cdot\left(1-G_{i}(-r)\right)\right] \\
& =\mathbb{E}\left[\left(1-\theta+\theta \mu_{i}^{1}\right) \cdot\left(1-G_{i}(-r)\right)\right]-\mathbb{E}\left[\left(1-\theta+\theta \mu_{i}^{0}\right) \cdot\left(1-G_{i}(-r)\right)\right] \\
& =\theta \mathbb{E}\left[\mu_{i}^{1}\left(1-G_{i}(-r)\right)-\theta \mu_{i}^{0} \cdot\left(1-G_{i}(-r)\right)\right] \\
& =\theta\left[\operatorname{Pr}_{i}(a=1 \mid j=1)-\operatorname{Pr}_{i}(a=1 \mid j=0)\right] .
\end{aligned}
$$


Similarly, following the proof of part 2, and using $\hat{V}_{i}$ and to denote perceived utilities, we have that

$$
\begin{aligned}
\frac{d}{d p} \frac{d}{d r} \mathbb{E}\left[\hat{V}_{i}(p, r)\right] & =\frac{d}{d p} \mathbb{E}\left[\frac{d}{d r} \hat{V}_{i}(p, r)\right] \\
& =\frac{d}{d p}\left[\operatorname{Pr}(j=1 \mid p, r) \mathbb{E}\left[\hat{\mu}_{i}^{1} \cdot\left(1-G_{i}(-r)\right)\right]+\operatorname{Pr}(j=1 \mid p, r) \mathbb{E} \mathbb{E}\left[\hat{\mu}_{i}^{0} \cdot\left(1-G_{i}(-r)\right)\right]\right] \\
& =\frac{d}{d p}\left[\operatorname{Pr}(j=1 \mid p, r) \mathbb{E}\left[\left(1-\theta+\theta \mu_{i}^{1}\right) \cdot\left(1-G_{i}(-r)\right)\right]\right] \\
& +\frac{d}{d p}\left[\operatorname{Pr}(j=0 \mid p, r) \mathbb{E}\left[\left(1-\theta+\theta \mu_{i}^{0}\right) \cdot\left(1-G_{i}(-r)\right)\right]\right] \\
& =\frac{d}{d p}[\operatorname{Pr}(j=1 \mid p, r)+\operatorname{Pr}(j=0 \mid p, r)](1-\theta) \\
& +\theta \frac{d}{d p}[\operatorname{Pr}(j=1 \mid p, r) \operatorname{Pr}(a=1 \mid j=1, r)+\operatorname{Pr}(j=0 \mid p, r) \operatorname{Pr}(a=1 \mid j=0, r)] \\
& =\theta \frac{d}{d p}[\operatorname{Pr}(j=1 \mid p, r) \operatorname{Pr}(a=1 \mid j=1, r)+\operatorname{Pr}(j=0 \mid p, r) \operatorname{Pr}(a=1 \mid j=0, r)] \\
& =\theta \frac{d}{d p} \operatorname{Pr}(a=1 \mid p, r)
\end{aligned}
$$

On the other hand,

$$
\begin{aligned}
\frac{d}{d r} \frac{d}{d p} \mathbb{E}\left[\hat{V}_{i}(p, r)\right] & =\frac{d}{d r} \mathbb{E}\left[\frac{d}{d p} \hat{V}_{i}(p, r)\right] \\
& =-\frac{d}{d r} \operatorname{Pr}(j=1 \mid p, r)
\end{aligned}
$$

It thus follows that

$$
\frac{d}{d r} \operatorname{Pr}(j=1)=-\theta \frac{d}{d p} \operatorname{Pr}(a=1) .
$$




\section{B Additional results and screenshots for experiment 1}

B.1 Additional results 
Table B.1: The Effect of Coding-Task Incentives on Coding Task Completion

\begin{tabular}{|c|c|c|c|}
\hline & $\begin{array}{c}(1) \\
\text { Week } 1\end{array}$ & $\begin{array}{c}(2) \\
\text { Weeks 1-4 }\end{array}$ & $\begin{array}{c}(3) \\
\text { Weeks 1-8 }\end{array}$ \\
\hline$>0$ & $\begin{array}{c}0.036^{* * *} \\
(0.009)\end{array}$ & $\begin{array}{c}0.032^{* * *} \\
(0.007)\end{array}$ & $\begin{array}{c}0.026^{* * *} \\
(0.006)\end{array}$ \\
\hline Obs. & 714 & 714 & 714 \\
\hline $\mathrm{R}^{2}$ & 0.039 & 0.059 & 0.064 \\
\hline Control Mean & 0.385 & 0.278 & 0.210 \\
\hline$>10$ & $\begin{array}{c}0.037^{* * *} \\
(0.009)\end{array}$ & $\begin{array}{c}0.034^{* * *} \\
(0.007)\end{array}$ & $\begin{array}{c}0.027^{* * *} \\
(0.006)\end{array}$ \\
\hline Obs. & 714 & 714 & 714 \\
\hline $\mathrm{R}^{2}$ & 0.047 & 0.067 & 0.072 \\
\hline Control Mean & 0.339 & 0.243 & 0.179 \\
\hline$>30$ & $\begin{array}{c}0.036^{* * *} \\
(0.009)\end{array}$ & $\begin{array}{c}0.027^{* * *} \\
(0.006)\end{array}$ & $\begin{array}{c}0.023^{* * *} \\
(0.005)\end{array}$ \\
\hline Obs. & 714 & 714 & 714 \\
\hline $\mathrm{R}^{2}$ & 0.043 & 0.053 & 0.068 \\
\hline Control Mean & 0.239 & 0.186 & 0.138 \\
\hline$>40$ & $\begin{array}{c}0.038^{* * *} \\
(0.009)\end{array}$ & $\begin{array}{c}0.026^{* * *} \\
(0.006)\end{array}$ & $\begin{array}{c}0.021^{* * *} \\
(0.005)\end{array}$ \\
\hline Obs. & 714 & 714 & 714 \\
\hline $\mathrm{R}^{2}$ & 0.044 & 0.058 & 0.074 \\
\hline Control Mean & 0.183 & 0.161 & 0.119 \\
\hline$>50$ & $\begin{array}{c}0.032^{* * *} * \\
(0.008)\end{array}$ & $\begin{array}{c}0.022^{* * *} \\
(0.005)\end{array}$ & $\begin{array}{c}0.017^{* * *} \\
(0.004)\end{array}$ \\
\hline Obs. & 714 & 714 & 714 \\
\hline $\mathrm{R}^{2}$ & 0.037 & 0.058 & 0.071 \\
\hline Control Mean & 0.165 & 0.142 & 0.107 \\
\hline$>60$ & $\begin{array}{c}0.027^{* * *} \\
(0.008)\end{array}$ & $\begin{array}{c}0.019^{* * *} \\
(0.005)\end{array}$ & $\begin{array}{c}0.013^{* * *} \\
(0.004)\end{array}$ \\
\hline Obs. & 714 & 714 & 714 \\
\hline $\mathrm{R}^{2}$ & 0.044 & 0.066 & 0.066 \\
\hline Control Mean & 0.138 & 0.118 & 0.093 \\
\hline Controls & Yes & Yes & Yes \\
\hline Campus $\times$ Student FE & Yes & Yes & Yes \\
\hline
\end{tabular}

This table presents estimates for the effect of coding-task incentives (in dollars) on coding task completion. Each panel of the table corresponds to an analysis of whether participants completed at least that number of minutes of the coding task in a given week. The columns correspond to different periods during the experiment over which the effect of the incentives is tested: Column (1) shows the effect in the first week, Column (2) shows the effect during the first four weeks, and Column (3) shows the effect over the entire experiment. In Column (1), the dependent variable is an indicator for whether a participant completed at least that many minutes of the coding task in the first week. In Columns (2) and (3), the dependent variable is the mean of the indicators, constructed as in Column (1), for each of the weeks being considered. Each panel-by-column corresponds to a separate specification, and thus 18 distinct specifications are shown in the table. Standard errors are shown in parentheses. ${ }^{*} p<0.1,{ }^{* *} p<0.05,{ }^{* * *} p<0.01$ 
Table B.2: The Effect of Plan-Making Incentives on Coding Task Completion

\begin{tabular}{|c|c|c|c|}
\hline & $\begin{array}{c}(1) \\
\text { Week } 1\end{array}$ & $\begin{array}{c}(2) \\
\text { Weeks 1-4 }\end{array}$ & $\begin{array}{c}(3) \\
\text { Weeks 1-8 }\end{array}$ \\
\hline$>0$ & $\begin{array}{l}0.037^{*} \\
(0.022)\end{array}$ & $\begin{array}{l}0.029^{*} \\
(0.015)\end{array}$ & $\begin{array}{c}0.014 \\
(0.012)\end{array}$ \\
\hline Obs. & 705 & 705 & 705 \\
\hline $\mathrm{R}^{2}$ & 0.041 & 0.040 & 0.046 \\
\hline Control Mean & 0.385 & 0.278 & 0.210 \\
\hline$>10$ & $\begin{array}{l}0.037^{*} \\
(0.021)\end{array}$ & $\begin{array}{l}0.027^{*} \\
(0.014)\end{array}$ & $\begin{array}{c}0.014 \\
(0.011)\end{array}$ \\
\hline Obs. & 705 & 705 & 705 \\
\hline $\mathrm{R}^{2}$ & 0.045 & 0.045 & 0.046 \\
\hline Control Mean & 0.339 & 0.243 & 0.179 \\
\hline$>30$ & $\begin{array}{c}0.045^{* *} \\
(0.020)\end{array}$ & $\begin{array}{l}0.023^{*} \\
(0.013)\end{array}$ & $\begin{array}{c}0.010 \\
(0.010)\end{array}$ \\
\hline Obs. & 705 & 705 & 705 \\
\hline & 0.054 & 0.042 & 0.045 \\
\hline Control Mean & 0.239 & 0.186 & 0.138 \\
\hline$>40$ & $\begin{array}{c}0.036^{* *} \\
(0.018)\end{array}$ & $\begin{array}{c}0.019 \\
(0.012)\end{array}$ & $\begin{array}{c}0.008 \\
(0.009)\end{array}$ \\
\hline Obs. & 705 & 705 & 705 \\
\hline $\mathrm{R}^{2}$ & 0.034 & 0.036 & 0.041 \\
\hline Control Mean & 0.183 & 0.161 & 0.119 \\
\hline$>50$ & $\begin{array}{l}0.034^{*} \\
(0.018)\end{array}$ & $\begin{array}{c}0.015 \\
(0.011)\end{array}$ & $\begin{array}{c}0.005 \\
(0.008)\end{array}$ \\
\hline Obs. & 705 & 705 & 705 \\
\hline & 0.035 & 0.039 & 0.042 \\
\hline Control Mean & 0.165 & 0.142 & 0.107 \\
\hline$>60$ & $\begin{array}{l}0.027^{*} \\
(0.016)\end{array}$ & $\begin{array}{c}0.013 \\
(0.010)\end{array}$ & $\begin{array}{c}0.002 \\
(0.008)\end{array}$ \\
\hline Obs. & 705 & 705 & 705 \\
\hline $\mathrm{R}^{2}$ & 0.044 & 0.038 & 0.042 \\
\hline Control Mean & 0.138 & 0.118 & 0.093 \\
\hline Controls & Yes & Yes & Yes \\
\hline Campus $\times$ Student FE & Yes & Yes & Yes \\
\hline
\end{tabular}

This table presents estimates for the effect of plan-making incentives (in dollars) on coding task completion. Each panel of the table corresponds to an analysis of whether participants completed at least that number of minutes of the coding task in a given week. The columns correspond to different periods during the experiment over which the effect of the incentives is tested: Column (1) shows the effect in the first week, Column (2) shows the effect during the first four weeks, and Column (3) shows the effect over the entire experiment. In Column (1), the dependent variable is an indicator for whether a participant completed at least that many minutes of the coding task in the first week. In Columns (2) and (3), the dependent variable is the mean of the indicators, constructed as in Column (1), for each of the weeks being considered. Each panel-by-column corresponds to a separate specification, and thus 18 distinct specifications are shown in the table. Standard errors are shown in parentheses. ${ }^{*} p<0.1,{ }^{* *} p<0.05,{ }^{* * *} p<0.01$ 
Table B.3: The Effect of Plan-Making Incentives on Coding Task Completion (2SLS)

\begin{tabular}{lccc} 
Panel A: The Effect on Plan Making (First Stage) & \\
\hline & $(1)$ & $(2)$ & $(3)$ \\
& Week 1 & Weeks 1-4 & Weeks 1-8 \\
\hline \$1 Plan & $0.282^{* * *}$ & $0.285^{* * *}$ & $0.240^{* * *}$ \\
& $(0.048)$ & $(0.033)$ & $(0.030)$ \\
\$2 Plan & $0.368^{* * *}$ & $0.297^{* * *}$ & $0.242^{* * *}$ \\
& $(0.033)$ & $(0.028)$ & $(0.025)$ \\
\hline Obs. & 705 & 705 & 705 \\
$\mathrm{R}^{2}$ & 0.144 & 0.189 & 0.157 \\
Control Mean & 0.381 & 0.150 & 0.082 \\
Controls & Yes & Yes & Yes \\
Campus FE & Yes & Yes & Yes \\
\hline
\end{tabular}

Panel B: The Effect on Coding Task Completion (Reduced Form)

\begin{tabular}{|c|c|c|c|c|c|c|}
\hline & $\begin{array}{c}(1) \\
>20(1)\end{array}$ & $\begin{array}{c}(2) \\
>20(1-4)\end{array}$ & $\begin{array}{c}(3) \\
>20(1-8)\end{array}$ & $\begin{array}{c}(4) \\
>45(1)\end{array}$ & $\begin{array}{c}(5) \\
>45(1-4)\end{array}$ & $\begin{array}{c}(6) \\
>45^{(1-8)}\end{array}$ \\
\hline$\$ 1$ Plan & $\begin{array}{c}0.034 \\
(0.048)\end{array}$ & $\begin{array}{c}0.017 \\
(0.032)\end{array}$ & $\begin{array}{c}0.013 \\
(0.025)\end{array}$ & $\begin{array}{c}0.034 \\
(0.043)\end{array}$ & $\begin{array}{l}-0.000 \\
(0.027)\end{array}$ & $\begin{array}{c}0.005 \\
(0.021)\end{array}$ \\
\hline$\$ 2$ Plan & $\begin{array}{l}0.079^{*} \\
(0.040)\end{array}$ & $\begin{array}{c}0.054^{* *} \\
(0.027)\end{array}$ & $\begin{array}{c}0.026 \\
(0.021) \\
\end{array}$ & $\begin{array}{c}0.076^{* *} \\
(0.036)\end{array}$ & $\begin{array}{c}0.032 \\
(0.023) \\
\end{array}$ & $\begin{array}{c}0.012 \\
(0.018)\end{array}$ \\
\hline Obs. & 705 & 705 & 705 & 705 & 705 & 705 \\
\hline $\mathrm{R}^{2}$ & 0.057 & 0.049 & 0.051 & 0.036 & 0.035 & 0.041 \\
\hline Control Mean & 0.280 & 0.212 & 0.158 & 0.174 & 0.156 & 0.116 \\
\hline Controls & Yes & Yes & Yes & Yes & Yes & Yes \\
\hline Campus FE & Yes & Yes & Yes & Yes & Yes & Yes \\
\hline \multicolumn{7}{|c|}{ Panel C: The Effect of Plan Making on Coding Task Completion (IV) } \\
\hline & $\begin{array}{c}(1) \\
>20(1)\end{array}$ & $\begin{array}{c}(2) \\
>20^{(1-4)}\end{array}$ & $\begin{array}{c}(3) \\
>20^{(1-8)}\end{array}$ & $\begin{array}{c}(4) \\
>45(1)\end{array}$ & $\begin{array}{c}(5) \\
>45^{(1-4)}\end{array}$ & $\begin{array}{c}(6) \\
>45^{(1-8)}\end{array}$ \\
\hline Plan Making & $\begin{array}{c}0.203^{* *} \\
(0.102)\end{array}$ & $\begin{array}{l}0.146^{*} \\
(0.080)\end{array}$ & $\begin{array}{c}0.092 \\
(0.078)\end{array}$ & $\begin{array}{c}0.197^{* *} \\
(0.093)\end{array}$ & $\begin{array}{c}0.076 \\
(0.070)\end{array}$ & $\begin{array}{c}0.041 \\
(0.066)\end{array}$ \\
\hline Obs. & 705 & 705 & 705 & 705 & 705 & 705 \\
\hline $\mathrm{R}^{2}$ & 0.143 & 0.151 & 0.120 & 0.091 & 0.094 & 0.076 \\
\hline Control Mean & 0.280 & 0.212 & 0.158 & 0.174 & 0.156 & 0.116 \\
\hline Controls & Yes & Yes & Yes & Yes & Yes & Yes \\
\hline Campus FE & Yes & Yes & Yes & Yes & Yes & Yes \\
\hline
\end{tabular}

This table shows estimates for the effect of plan-making incentives on plan making and coding task completion using treatment dummies rather than a linear plan-making incentive variable. Panel A shows estimates of the effect of plan-making incentives on whether or not participants made a plan. Column (1) shows the effect of plan-making incentives in the first week of the experiment. Column (2) shows the average effect over the first four weeks. Column (3) shows the average effect over the entire experiment. Panel B shows the effect of plan-making incentives on coding task completion. Columns (1-3) show the effect on an indicator variable for whether or not the participant worked on the coding task for more than 20 minutes: Column (1) estimates the effect over the first week, Column (2) over the first four weeks, and Column (3) over the entire experiment. Columns (4-6) show analogous estimates, but for an indicator variable for whether or not the participant worked on the coding task for more than 45 minutes each week. Panel C shows the 2SLS estimates instrumenting for whether or not participants made a plan using the plan-making treatment dummies as instruments. The dependent variables are the same as those in Panel B. Standard errors are shown in parentheses. ${ }^{*} p<0.1,{ }^{* *} p<0.05,{ }^{* * *} p<0.01$. 


\section{B.2 Screenshots}

Figure B.1: Pay-to-Plan Treatment Emails, Week 1 \$1 Plan-Making Incentive

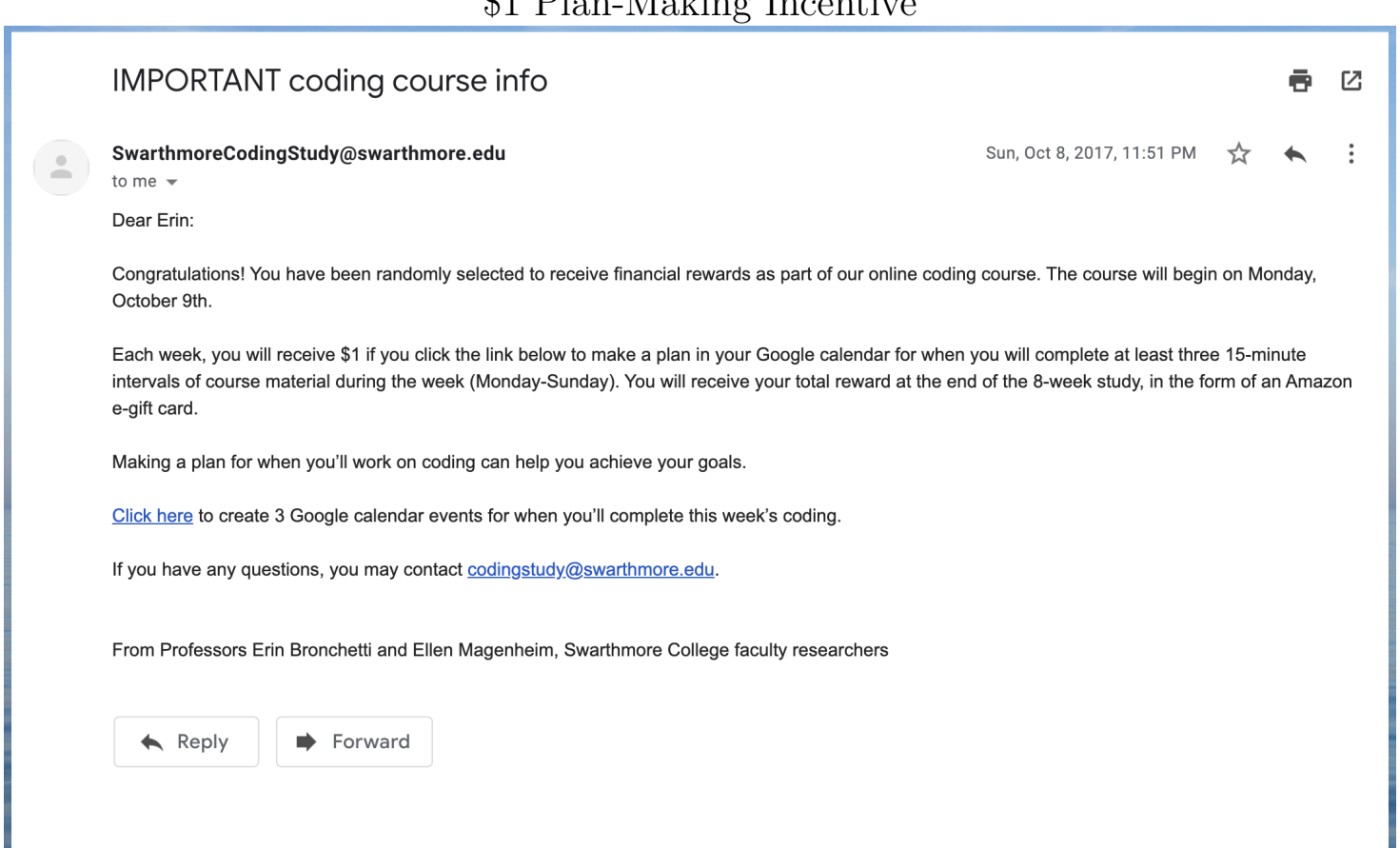

\section{\$2 Plan-Making Incentive}

IMPORTANT coding course info

SwarthmoreCodingStudy@swarthmore.edu

to me -

Dear Erin:

Congratulations! You have been randomly selected to receive financial rewards as part of our online coding course. The course will begin on Monday, October 9th.

Each week, you will receive $\$ 2$ if you click the link below to make a plan in your Google calendar for when you will complete at least three 15-minute intervals of course material during the week (Monday-Sunday). You will receive your total reward at the end of the 8-week study, in the form of an Amazon e-gift card.

Making a plan for when you'll work on coding can help you achieve your goals.

Click here to create 3 Google calendar events for when you'll complete this week's coding.

If you have any questions, you may contact codingstudy@swarthmore.edu.

From Professors Erin Bronchetti and Ellen Magenheim, Swarthmore College faculty researchers
Forward 
Figure B.2: Pay-to-Code Treatment Emails, Week 1

$\$ 2$ Coding-Task Incentive

IMPORTANT coding course info

- SwarthmoreCodingStudy@swarthmore.edu

Sun, Oct 8, 2017, 11:50 PM 负

to me -

Dear Erin:

Congratulations! You have been randomly selected to receive financial rewards for completing parts of the online coding course. The course will begin on Monday, October 9th

Each week, you will receive $\$ 2$ if you complete at least three 15 -minute intervals of course material during that week (Monday-Sunday). You will receive your total reward at the end of the 8-week study, in the form of an Amazon e-gift card.

Making a plan for when you'll work on coding can help you achieve your goals.

Click here to create 3 Google calendar events for when you'll complete this week's coding

If you have any questions, you may contact codingstudy@swarthmore.edu.

From Professors Erin Bronchetti and Ellen Magenheim, Swarthmore College faculty researchers

h Reply $\Rightarrow$ Forward

\section{$\$ 5$ Coding-Task Incentive}

IMPORTANT coding course info

SwarthmoreCodingStudy@swarthmore.edu

Sun, Oct $8,2017,11: 50 \mathrm{PM}$

to me -

Dear Erin:

Congratulations! You have been randomly selected to receive financial rewards for completing parts of the online coding course. The course will begin on Monday, October 9th.

Each week, you will receive $\$ 5$ if you complete at least three 15 -minute intervals of course material during that week (Monday-Sunday). You will receive your total reward at the end of the 8-week study, in the form of an Amazon e-gift card.

Making a plan for when you'll work on coding can help you achieve your goals.

Click here to create 3 Google calendar events for when you'll complete this week's coding

If you have any questions, you may contact codingstudy@swarthmore.edu.

From Professors Erin Bronchetti and Ellen Magenheim, Swarthmore College faculty researchers

Reply

Forward 
Figure B.3: Combined and Control Group Emails, Week 1 Combined Treatment (\$1 Plan-Making and $\$ 2$ Coding-Task Incentive)

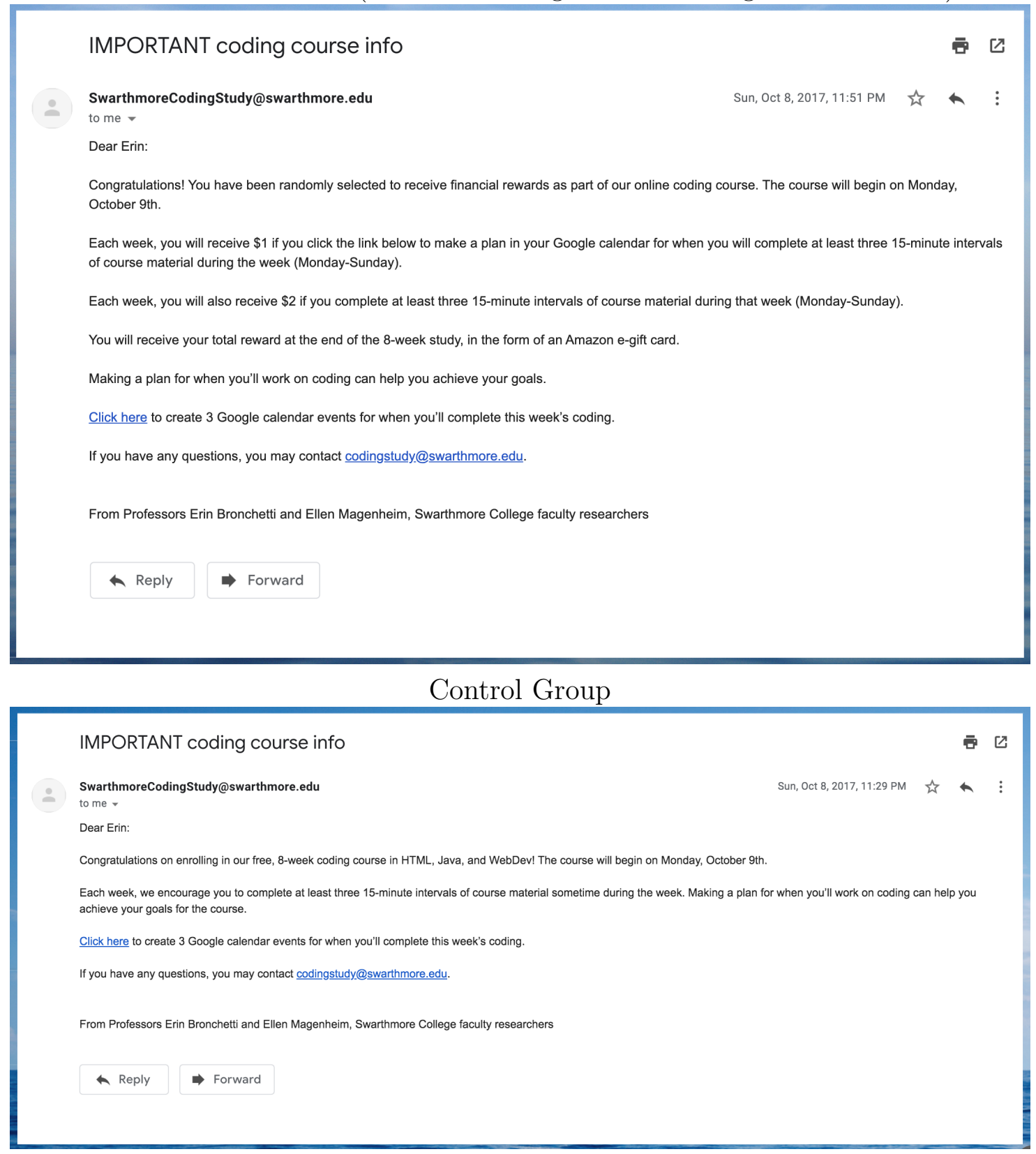




\section{Figure B.4: Weekly Reminder Email, All Groups}

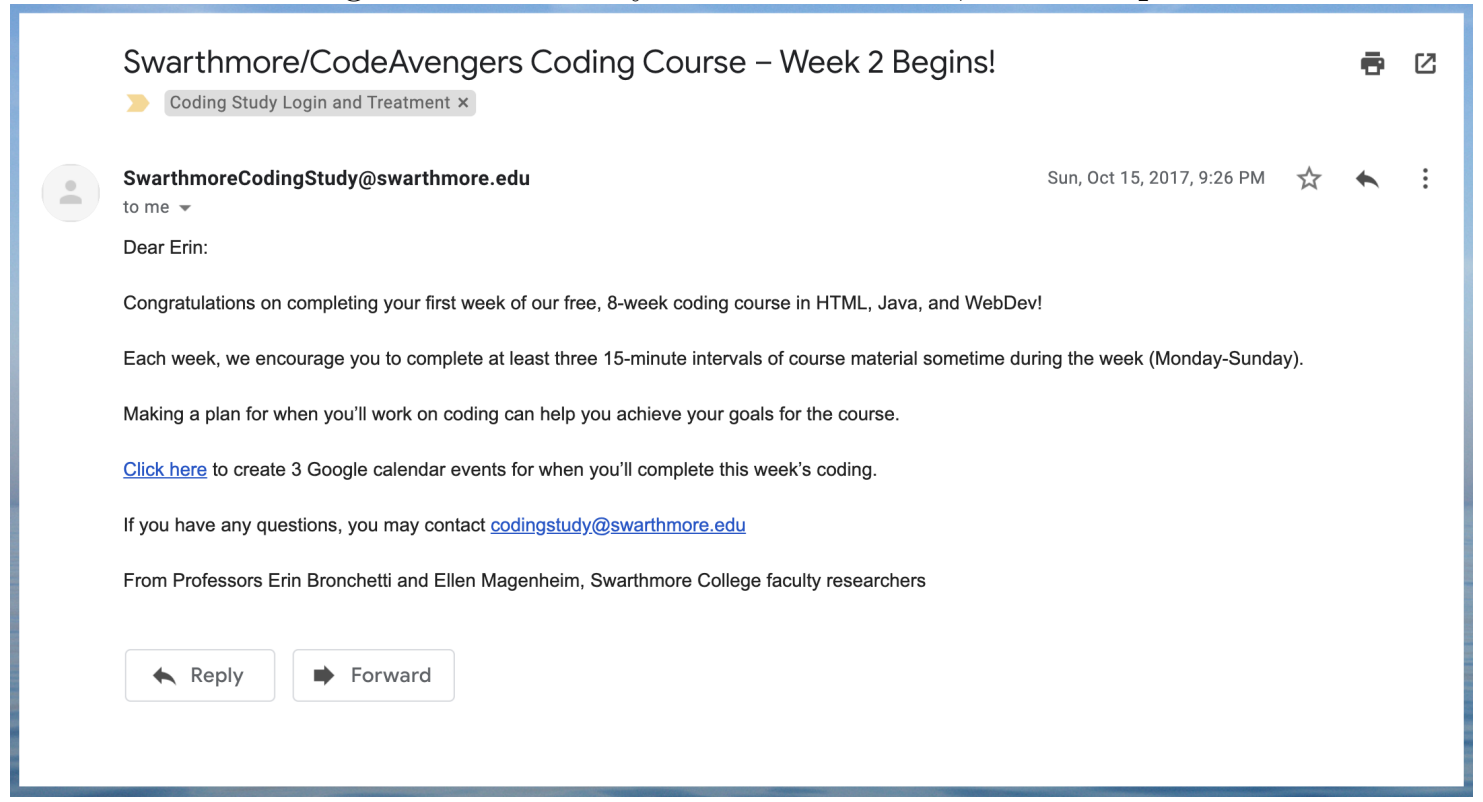




\section{Additional sample details, results, and screenshots for experiment 2}

\section{C.1 Sample details}

A total of 1,330 participants were recruited for our study, and we analyze data from 944 . The other 386 individuals were excluded from the study for one of the following seven reasons:

1. [14 individuals] Indicating that they were unavailable during the window when they would have needed to complete the survey in the second part of the study (see Appendix Figure C.1).

2. [12 individuals] Incorrectly entering the captcha both times it was asked of them (see Appendix Figures C.4 and C.5).

3. [245 individuals] Incorrectly answered one or both of the understanding questions about the reminders and bonus structure (see Appendix Figure C.7).

4. [25 individuals] Did not complete the first part of the study.

5. [79 individuals] Responding inconsistently on at least one of the MPL responses.

6. [4 individuals] Attempting to complete the first part of the study after the recruitment quota had been filled.

7. [7 individuals] Providing an invalid MTurk ID.

Note that we have no data from anyone excluded for one of the first three reasons. These individuals were excluded from continuing from the study based on their response (see, for example, Appendix Figure C.2, which was shown to those excluded for reason 1). In all cases, participants were excluded immediately after they: indicated that they would be unavailable to complete part 2 (reason 1), failed the captcha the second time (reason 2), or answered an understanding question incorrectly (reason 3). Participants who were excluded in this way did not provide any answers to any of the MPL questions. An advantage of excluding these participants from the study ex ante - rather than collecting their data and excluding it ex post - is that it ties our hands to only analyze data from participants who are attentive and clearly understand the study instructions.

We have incomplete data from anyone excluded for the fourth reason. These first four groups total 296 individuals. Consequently, we have complete responses to part 1 from 1,034 participants, which is the number reported in the main text. 
As indicated in the fifth reason for exclusion, 79 participants answered inconsistently on one or more MPLs. These participants may have misunderstood the MPL or made choices randomly. We drop them because we cannot define a WTP for the reminder emails when responses are inconsistent on the MPL.

\section{C.2 Additional results}

Table C.1: Willingness to Pay for Reminders: Randomized 90\%

\begin{tabular}{|c|c|c|c|c|}
\hline & $\begin{array}{c}(1) \\
\text { OLS } \\
\mathrm{WTP}^{(\$)}\end{array}$ & $\begin{array}{c}(2) \\
\text { OLS } \\
\operatorname{WTP}(\$)\end{array}$ & $\begin{array}{c}(3) \\
\text { OLS } \\
\operatorname{WTP}(\$)\end{array}$ & $\begin{array}{c}(4) \\
\text { Tobit } \\
\text { WTP }(\$)\end{array}$ \\
\hline Incentive $(\$)$ & $\begin{array}{c}0.15^{* * *} \\
(0.012)\end{array}$ & $\begin{array}{c}0.17 * * * \\
(0.027)\end{array}$ & $\begin{array}{c}0.17^{* * *} \\
(0.021)\end{array}$ & $\begin{array}{c}0.06 * * * \\
(0.006)\end{array}$ \\
\hline Observations & 3396 & 3395 & 3396 & 3396 \\
\hline Number of Participants & 849 & 849 & 849 & 849 \\
\hline Participant FE & Yes & Yes & Yes & No \\
\hline Mean WTP, \$2 Incentive & 0.50 & 0.60 & 0.94 & 0.43 \\
\hline Censoring Specification & Median Survey & Survey Resp. & $\$ 5$ Top & Tobit \\
\hline
\end{tabular}

This table presents estimates of how individual's willingness to pay (WTP) for reminders varies with incentives for the $90 \%$ of participants who were randomly assigned to receive or not receive the reminders. The columns vary how they treat censored responses -i.e., responses that were at the boundary of the multiple price list presented to participants. In Column (1), we replace a participant's WTP if they are top-censored with the median reported WTP from an unincentivized survey question among all top-censored participants within a particular incentive level. In Column (2), we replace this value with the participant's own reported WTP from that unincentivized survey question. In Column (3), we replace this value with $\$ 5.00$. In Column (4), we estimate the regression using a Tobit estimator. Values are represented in dollars. The number of observations falls by one in Column (2) because one participant did not complete one of the survey questions. Standard errors, clustered by participant, are shown in parentheses. ${ }^{*} p<0.1,{ }^{* *} p<0.05,{ }^{* * *} p<0.01$. 
Table C.2: Willingness-to-Pay by Experimental Incentive Ordering

\begin{tabular}{lcccc}
\hline & $\$ 2$ Incentive & $\$ 3$ Incentive & $\$ 4$ Incentive & $\$ 5$ Incentive \\
1st Incentive & 0.53 & 0.66 & 0.79 & 0.77 \\
& $(0.044)$ & $(0.058)$ & $(0.079)$ & $(0.079)$ \\
1st and 2nd Incentive & 0.50 & 0.64 & 0.77 & 0.83 \\
& $(0.030)$ & $(0.042)$ & $(0.054)$ & $(0.055)$ \\
1st-3rd Incentive & 0.49 & 0.61 & 0.81 & 0.87 \\
& $(0.026)$ & $(0.034)$ & $(0.043)$ & $(0.045)$ \\
All Incentives & 0.49 & 0.60 & 0.82 & 0.91 \\
& $(0.022)$ & $(0.029)$ & $(0.038)$ & $(0.040)$ \\
\hline
\end{tabular}

This table presents the average willingness to pay (WTP) for reminders in each incentive level, by order in which it was answered by participants. The columns vary by incentive level. The first three rows report average WTP for reminders at that incentive level for all participants for whom that incentive was: (i) the first incentive that they were asked about; (ii) the first or second incentive; (iii) the first, second, or third incentive. The fourth row shows all the data. The censored responses are treated as in column (1) of Table 4, we replace a participant's WTP if they are top-censored with the median reported WTP from an unincentivized survey question among all top-censored participants within a particular incentive level. Standard errors, clustered by participant, are shown in parentheses. ${ }^{*} p<0.1,{ }^{* *} p<0.05,{ }^{* * *} p<0.01$. 


\section{C.3 Screenshots}

Figure C.1: Eligibility Screen

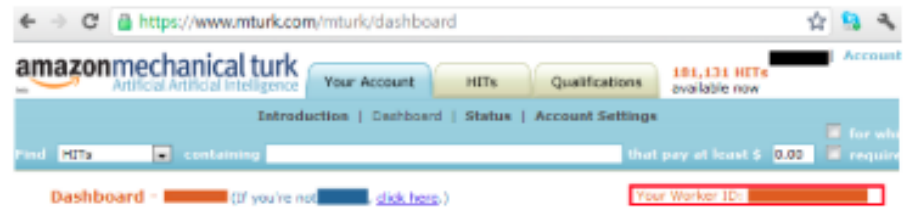

To determine whether you are eligible to participate in the study, please enter your Mechanical Turk Worker ID into the box below and answer the following two questions.

(See above for where you can find your Worker ID. Your Worker ID starts with the letter A and has 12-14 letters or numbers. It must be all CAPITAL letters and no spaces. It is NOT your email address.)

Are you available to participate now for 5-10 minutes and can you be available to participate for approximately 20 minutes between Wednesday, May 29 th and Tuesday, June 4th?

Yes

No

\section{$>s$}

This is the screen in which the participant entered his or her MTurk ID and indicated availability to complete part 2 of the study in the designated window.

Figure C.2: If Ineligible Screen

You have either participated in this (or a similar study) before or do not meet our eligibility criteria.

You are therefore not eligible to participate.

Thanks for your interest in our studies.

If participants had participated in the study at an earlier date or indicated they were not available in the designated window, they were shown this screen and excluded from participating. 


\section{Figure C.3: Consent Form}

This is a consent form. Please read and click below to continue.

Study Background and Purpose: This study examines decision-making. Your participation in this research will take approximately 5 to 10 minutes today and you will have the option to complete an additional task for approximately 20 minutes between Wednesday, May 29th and Tuesday, June 4th.

What Happens in this Research Study: If you decide to participate, you will answer questions.

Payments: There are no known costs to you for participating in this research study except for your time. Upon completion of the survey, you will be given a code that you can submit to MTurk so that you can receive your payment. You will be paid $\$ 1$ for completing the entire survey today, and you will have the possibility of earning an additional bonus payment today and an opportunity to eam an additional bonus payment at a later date.

Confidentiality: Your data will be anonymous and will not be linked to your identity.

Voluntary Participation: Participating in this research is voluntary. You can withdraw from the study at any time.

Contact: If you have questions, concerns, or complaints regarding this research, please contact the researcher at upenn.experiments@gmail.com. If a member of the research team cannot be reached or you want to talk to someone other than those working on the study, you may contact the Office of Regulatory Affairs with any question, concerns or complaints at the University of Pennsylvania by calling (215) 898-2614.

\section{Agreement to Participate}

By clicking to continue, you are indicating that you have read this consent form and that you voluntarily agree to participate in the study.

\section{Figure C.4: Attention Check (first attempt)}

\section{T2YKA}

Please type the sequence above into the text box below. The sequence is case sensitive. 
Figure C.5: Attention Check (second attempt)

\title{
T2YKA
}

Your first attempt was incorrect. You must enter the correct sequence in order to remain in the study.

Please type the sequence above into the text box below. The sequence is case sensitive.

If participants answered the attention check question incorrectly the first time, they saw this screen which warned them that failure to enter the sequence correctly would remove them from the study.

Figure C.6: Instructions, Screen 1

\begin{abstract}
Thank you for participating in this HIT. This HIT has two parts. The first part should take 5 to 10 minutes to complete. For completing the first part, you will earn \$1. You may also earn a "part 1 bonus" payment.

In the second part of the study, you'll be asked to take a survey that will last about 20 minutes and must be completed in one sitting. If you complete part 2 of the study, you will earn a "part 2 bonus" payment of \$2, \$3, \$4, or \$5. You cannot complete part 2 of the study now. You can only complete part 2 starting a week from tomorrow and you will bave three days to complete it.
\end{abstract}

In particular, at the end of this part of the study, you will receive a link to complete part 2 of the study. The link will become active at 12:01am Eastern Time (ET) on Wednesday, May 29 th and will remain active until 11:59pm ET on Tuesday, June 4th. You are required to complete part 2 of the study in one sitting within that time frame.

In this part of the study, we will ask you questions about bow you value receiving a set of three reminder emails to complete part 2 of the study. Based on random chance and your choices in part 1 of the study, you may receive a set of three reminder emails through the MTurk platform. If you do not receive this set of three reminder emails, we will not send you any reminders to complete part 2 of this study. 
Figure C.7: Understanding Questions for Instructions, Screen 1

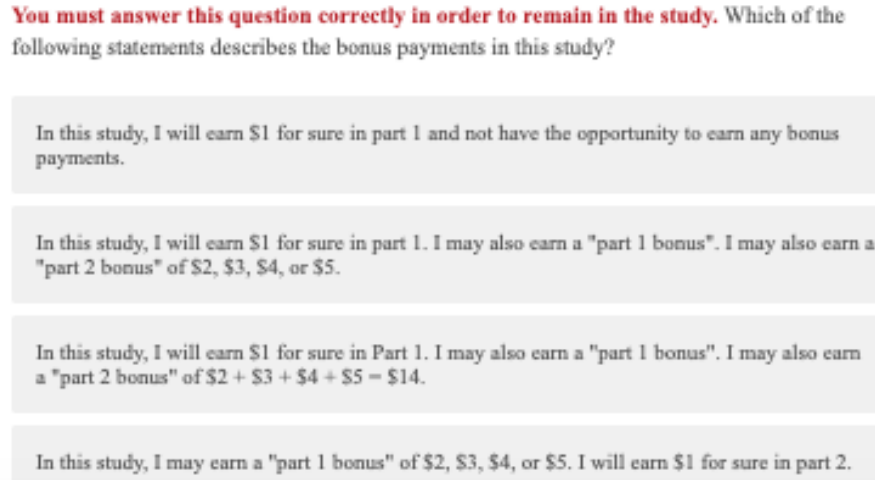

You must answer this question correctly in order to remain in the study. You will not receive any reminders unless you are selected to get them based on random chance and your choices in part 1 .

True

False 
Figure C.8: Instructions, Screen 2

If you receive the set of three reminder emails to complete part 2 of the study, we will send you three emails. Each email will include a link to access part 2 of the study.

We will send you the first reminder email at 12pm ET on Wednesday, May 29th, the day part 2 of the study opens.

We will send you the second reminder email at 12pm ET on Saturday, June 1st, halfway through the window to complete part 2 of the study.

We will send you the third reminder email at $12 \mathrm{pm}$ ET on Tuesday, June 4th, twelve hours before the window to complete part 2 of the study closes.

The emails will be sent to you through the MTurk platform. 
Figure C.9: Instructions, Screen 3

We will now ask you questions about how you value getting the three reminder emails to complete part 2 of the study.

You will be asked four sets of questions about how you value the reminder emails, one for each possible "part 2 bonus" payment that you might be eligible to receive.

\section{Each set of questions will apply to a different possible "part 2 bonus" payment for completing part 2 of the study. The possible "part 2 bonus" payments are $\$ 2, \$ 3, \$ 4$, and} $\$ 5$.

You cannot affect which "part 2 bonus" payment you are eligible to receive because it is randomly selected. Each possible bonus payment $(\$ 2, \$ 3, \$ 4$, and $\$ 5)$ will be randomly selected with $25 \%$ probability.

Instead, you will answer the questions on the following screens assuming that a particular "part 2 bonus" payment has been randomly selected. This means that your answers for a given "part 2 bonus" payment will only apply if that "part 2 bonus" payment is randomly selected.

In addition to the choices you make on the following screens, there is a chance that the computer will randomly assign you to either get the set of three reminder emails or not get the set of three reminder emails. 


\title{
Figure C.10: Example Multiple Price List with Incentive Level of $\$ 2$ If the "part 2 bonus" payment is randomly selected to be \$2...
}

\author{
If the "part $\mathbf{2}$ bonus" payment is randomly selected to be $\mathbf{\$ 2}$, either the computer \\ will determine whether or not you get reminders, and you will receive a "part 1 bonus" of 100 \\ cents, or one of the 11 rows below will be randomly selected and whatever you have chosen in \\ that row will be implemented. If one of the rows below is randomly selected, then:
}

If you choose the option on the left, you will get the three reminder emails. You will also receive the "part 1 bonus" payment listed in the option on the left.

If you choose the option on the right, you will NOT get the three reminder emails. You will also receive the "part 1 bonus" payment listed in the option on the right.

Note that the "part 1 bonus" payment will be delivered a few days after completion of part 1 of the study and the "part 2 bonus" payment will only be delivered if you complete part 2 of the study in one sitting in the designated time frame.

Please choose whether you prefer the option on the left or the option on the right in each row.

$\begin{array}{llll}\text { Get reminders + part } 1 \text { bonus of } 150 \text { cents } & \bigcirc & \bigcirc & \text { No reminders + part } 1 \text { bonus of } 0 \text { cents } \\ \text { Get reminders + part } 1 \text { bonus of } 100 \text { cents } & \bigcirc & \bigcirc & \text { No reminders + part } 1 \text { bonus of } 0 \text { cents } \\ \text { Get reminders + part } 1 \text { bonus of } 75 \text { cents } & \bigcirc & \bigcirc & \text { No reminders + part } 1 \text { bonus of } 0 \text { cents } \\ \text { Get reminders + part } 1 \text { bonus of } 50 \text { cents } & \bigcirc & \bigcirc & \text { No reminders + part } 1 \text { bonus of } 0 \text { cents } \\ \text { Get reminders + part } 1 \text { bonus of } 25 \text { cents } & \bigcirc & \bigcirc & \text { No reminders + part } 1 \text { bonus of } 0 \text { cents } \\ \text { Get reminders + part } 1 \text { bonus of } 0 \text { cents } & \bigcirc & \bigcirc & \text { No reminders + part } 1 \text { bonus of } 0 \text { cents } \\ \text { Get reminders + part } 1 \text { bonus of } 0 \text { cents } & \bigcirc & \bigcirc & \text { No reminders + part } 1 \text { bonus of } 25 \text { cents } \\ \text { Get reminders + part } 1 \text { bonus of } 0 \text { cents } & \bigcirc & \bigcirc & \text { No reminders + part } 1 \text { bonus of } 50 \text { cents } \\ \text { Get reminders + part } 1 \text { bonus of } 0 \text { cents } & \bigcirc & \bigcirc & \text { No reminders + part } 1 \text { bonus of } 75 \text { cents } \\ \text { Get reminders + part } 1 \text { bonus of } 0 \text { cents } & \bigcirc & \bigcirc & \text { No reminders + part } 1 \text { bonus of } 100 \text { cents } \\ \text { Get reminders + part } 1 \text { bonus of } 0 \text { cents } & \bigcirc & \bigcirc & \text { No reminders + part } 1 \text { bonus of } 150 \text { cents }\end{array}$

This figure shows the multiple price list when the incentive for completing the survey is $\$ 2$. In row 1 , the option on the left is to get a part 1 bonus payment of $\$ 1.50$ and the three reminder emails while the option on the right is to get no part 1 bonus payment and no reminder emails. In the next 5 rows (i.e., rows $2-6$ ), the option on the right remains the same while the option on the left has a part 1 bonus (that accompanies the reminder emails) that decreases in $\$ 0.25$ increments. In row 6 , participants choose between getting and not getting the reminder emails (with no part 1 bonus payment associated with either option). In the next 5 rows (i.e., rows $7-11$ ), the option on the left remains the same (i.e., getting the reminder emails and no part 1 bonus) while the option on the right has a part 1 bonus that increases in $\$ 0.25$ increments. In row 11 , the option on the left is to get the reminder emails and receive no part 1 bonus while the option on the right is to get no reminder emails and a part 1 bonus of $\$ 1.50$. Participants saw a version of this screen four times, once for each possible incentive for completing the survey: $\$ 2, \$ 3, \$ 4$, and $\$ 5$. The order of these four MPL questions were randomized at the participant lygel. 
Figure C.11: Unincentivized Question if Censored at $W T P \geq \$ 1.50$ This question will not affect your payment

You said that you prefer "Get reminders + part 1 bonus of 0 cents" to "No reminders + part 1 bonus of 150 cents". What is the smallest part 1 bonus that we could add to "No reminders" to make you prefer "No reminders" to "Get reminders + part 1 bonus of 0 cents"?

Please give your answer in cents.

Participants who chose the option on the left in the last row of the MPL, indicating they valued reminders more than $\$ 1.50$, were shown this screen to elicit an unincentivized willingness to pay beyond the $\$ 1.50$ maximum. Participants were required to enter a number that was greater than 150 cents.

Figure C.12: Unincentivized Question if Censored at $W T P \leq-\$ 1.50$ This question will not affect your payment

You said that you prefer "No reminders + part 1 bonus of 0 cents" to "Get reminders + part 1 bonus of 150 cents". What is the smallest part 1 bonus that we could add to "Get reminders" to make you prefer "Get reminders" to "No reminders + part 1 bonus of 0 cents"?

Please give your answer in cents.

Participants who chose the option on the right in the first row of the MPL, indicating they valued reminders less than $-\$ 1.50$, would have been shown this screen to elicit an unincentivized willingness to pay beyond the $-\$ 1.50$ minimum. Participants would have been required to enter a number that was greater than 150 cents. In practice, no participant was censored in this way and so this screen was never shown to participants. 
Figure C.13: Final Screen: No reminder emails

The following link will take you to part 2 of the study and be active from 12:01am ET on Wednesday, May 29th to 11:59pm ET on Tuesday, June 4th.

Please make a note of this link. You will not receive any reminders to take part 2 of the study.

https://wharton.qualtrics.com/jfe/form/SV_9An0Cwmn6mNjtU9

Participants who would not receive reminder emails were shown this screen at the end of part 1 of the study.

Figure C.14: Final Screen: Reminder emails

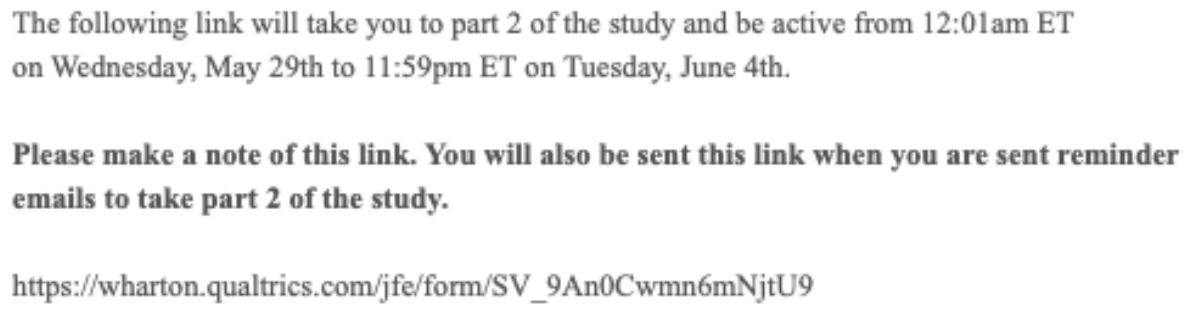

Participants who would receive reminder emails were shown this screen at the end of part 1 of the study. 